\title{
Aeroheating Design Issues for Reusable Launch Vehicles -- A Perspective
}

\author{
E. Vincent Zoby*, Richard A. Thompson ${ }^{\dagger}$, and Kathryn E. Wurster ${ }^{\ddagger}$ \\ NASA Langley Research Center, Hampton, VA 23681
}

\begin{abstract}
An overview of basic aeroheating design issues for Reusable Launch Vehicles (RLV), which addresses the application of hypersonic ground-based testing, and computational fluid dynamic (CFD) and engineering codes, is presented. Challenges inherent to the prediction of aeroheating environments required for the successful design of the RLV Thermal Protection System (TPS) are discussed in conjunction with the importance of employing appropriate experimental/computational tools. The impact of the information garnered by using these tools in the resulting analyses, ultimately enhancing the RLV TPS design is illustrated. A wide range of topics is presented in this overview; e.g. the impact of flow physics issues such as boundary-layer transition, including effects of distributed and discrete roughness, shockshock interactions, and flow separation/reattachment. Also, the benefit of integrating experimental and computational studies to gain an improved understanding of flow phenomena is illustrated. From computational studies, the effect of low-density conditions and of uncertainties in material surface properties on the computed heating rates are highlighted as well as the significant role of CFD in improving the Outer Mold Line (OML) definition to reduce aeroheating while maintaining aerodynamic performance. Appropriate selection of the TPS design trajectories and trajectory shaping to mitigate aeroheating levels and loads are discussed. Lastly, an illustration of an aeroheating design process is presented whereby data from hypersonic wind-tunnel tests are integrated with predictions from CFD codes and engineering methods to provide heating environments along an entry trajectory as required for TPS design.
\end{abstract}

\section{Introduction}

Over approximately the last decade, a significant effort has been expended by NASA and industry partners in trade studies examining design issues for RLVs. One technology area that has not always received sufficient emphasis in the vehicle design process, but is requisite to a successful mission, is the accurate determination of the aeroheating environment. The purpose of this paper is to present a perspective on technical issues related to the aeroheating design of reusable vehicles. While the announcement in January 2004 of a new vision for the United States civil space program based upon exploration of the moon, Mars, and beyond ushered in a return in interest to capsule vehicles (i.e. Apollo like), there nevertheless remains an interest within the Department of Defense community on reusable winged-body vehicles primarily because of their greater performance capability and operational flexibility. The present discussion will utilize existing computational and experimental research studies to illustrate the significance and relevance of the design issues highlighted herein, and will focus primarily on the understanding gained when appropriate tools are employed. The perspectives presented herein are parochial in the sense that they are limited to experiences/knowledge of the present authors. For example, the experimental aeroheating studies presented are based mainly on data gathered with the two-color relative-intensity phosphor thermography optical acquisition technique ${ }^{1}$ as applied in the Langley Aerothermodynamic Lab (LAL; comprised of three conventional-type blowdown hypersonic wind tunnels). This non-intrusive global technique has become the primary tool used in aeroheating studies conducted by the Aerothermodynamics Branch (AB) at the Langley Research Center (LaRC) and has proved to be extremely valuable to many studies of the X-vehicles, e. g., the X-33, $\mathrm{X}-34, \mathrm{X}-37, \mathrm{X}-38$, and X-43 as well as to the Space Shuttle Columbia accident investigation and return to flight

\footnotetext{
* Senior Research Engineer, Aerothermodynamics Branch, Mail Stop 408A, Fellow AIAA.

${ }^{\dagger}$ Senior Research Engineer, Aerothermodynamics Branch, Mail Stop 408A, Senior Member AIAA.

* Senior Research Engineer, Vehicle Analysis Branch, Mail Stop 365, Associate Fellow AIAA. 
activities. The method provides global information not available using discrete measurements such as thin-film gages. Similarly, the computational topics are based on tools developed and applied by the AB and the Vehicle Analysis Branch (VAB) at LaRC. The numerical results discussed in this paper were obtained with the Langley Aerothermodynamic Upwind Relaxation Algorithm² (LAURA), the Langley Approximate Three Dimensional Convective Heating ${ }^{3}$ (LATCH) and the MINIVER $^{4}$ codes. Computational and experimental topics will address several key issues, including boundary-layer transition, shock-shock interactions, flow separation/reattachment, lowdensity effects (viscous interactions), uncertainties in material surface properties, and factors in design trajectory selection. For the computational topics, no discussion will be allocated to algorithm assessment, surface or volume grid issues, or convergence schemes. The importance of these topics to RLV aeroheating design issues are significant, but are addressed in detail in many investigations (e.g. Ref. 2). A final section will provide an illustration of the coupling of the experimental and computational efforts to produce the required aeroheating data for TPS design.

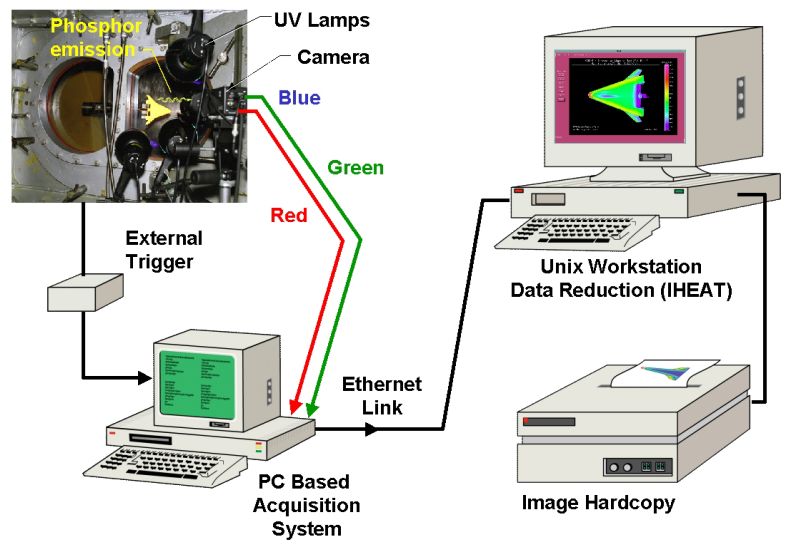

Fig. 1 Schematic of Langley two color thermographic phosphor system.

\section{Methodology}

In this section, a general overview of the experimental and analytical methods used by aerothermodynamic investigators at LaRC is presented. Appropriate integration of these methods in the existing studies has enabled researchers to focus attention to a high level of detail on issues critical to RLV aeroheating design efforts.

\section{A. Experimental Methods}

The heating data presented in the paper were measured with a two-color relative-intensity phosphor thermography measurement technique ${ }^{1}$. A sketch of this experimental optical acquisition system is shown in Fig. 1. A mixture of phosphors that fluoresce in the red and green visible spectrum is used to coat a slip cast silica ceramic model. The phosphors fluoresce when illuminated by ultraviolet light, and the intensity of the fluorescence is dependent upon the phosphor temperature. Fluorescent intensity images are acquired, and a pretest calibration allows for the fluoresced images to be converted to temperature values. The temperature data are then reduced to heat-transfer coefficients using a one-dimensional heat conduction analysis. These heating data have been compared $^{5}$ with corresponding data from thin-film gauges yielding very good results. The phosphor experimental heating technique has been the "work horse" for the LaRC AB aeroheating study programs for over a decade. There are two main advantages of this technique over conventional transient thin-skin calorimeter and thin-film resistance methods. The first is the global resolution of temperature/heating data that provides the detailed information of specific flow features. The second is that model fabrication is more rapid by more than an order of magnitude, and thus model costs are much less than models used for conventional test techniques. An example of the wealth of information that is provided with this experimental technique is shown in Fig. 2 where the variation in transition patterns with angle of attack (AOA) is illustrated in Ref. 6. At the lower AOA (Fig. 2(a)), two lobes define the transition onset boundary, and at the higher AOA (Fig. 2(b)), a parabolic shape defines the transition zone. The twolobe pattern in Fig. 2(a) is attributed in Ref. 7 to a turning-in of the streamlines resulting in a thicker boundary layer along the centerline. 


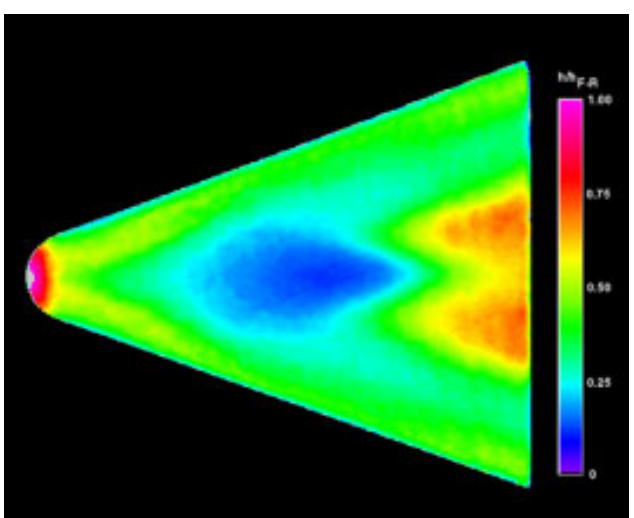

(a) $\alpha=30 \mathrm{deg}$

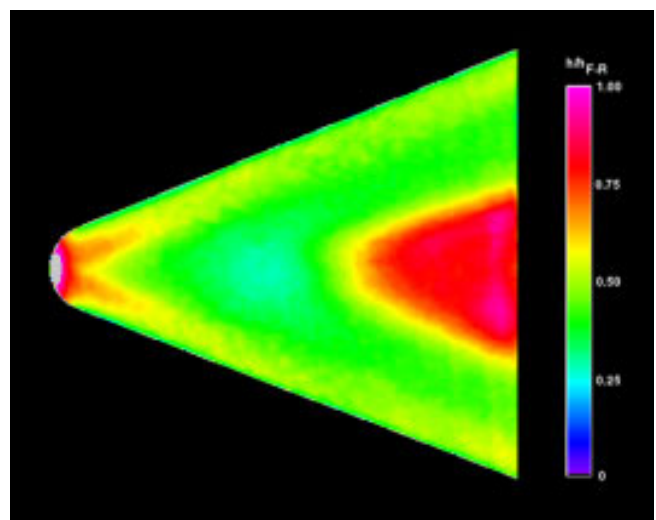

(b) $\alpha=40 \mathrm{deg}$

Fig. 2 Effect of angle of attack on "smooth" forebody transition for $M=6$ and $\operatorname{Re}=4 \times 10^{6} / \mathrm{ft}$.

Flow visualization information is obtained with schlieren systems and oil flows. The LaRC 20-inch Mach 6 Air Tunnel $^{8}$ is equipped with a pulsed white light Z-pattern single-pass schlieren system. The field of view includes the entire 20-inch test section. The oil-flow technique enables the tracing and analysis of surface streamline patterns and the observance of flow separation/reattachment regions.

While most of the data presented in this overview paper were measured in the Mach 6 air facility, it should be noted that good qualitative/quantitative heating data are also obtained in the 31-Inch Mach 10 Air Tunnel and the 20-Inch Mach 13-18 Simulator. Also, the experimental methods used in the schlieren and oil flow processes have been significantly upgraded over those used to obtain the data reviewed in this paper.

\section{B. Computational Methods}

LAURA $^{2}$ is a Navier Stokes code that is applied as a high speed viscous and inviscid flow solver, used primarily for steady conditions. The algorithm is based on a finite volume shock capturing upwind technique. LAURA includes perfect gas, equilibrium, thermal and chemical nonequilibrium air models for flowfield calculations as well as gas models for $\mathrm{CF}_{4}$ and for the major planets. The LAURA code is unique in its ability to perform grid adaptation during solution convergence to resolve boundary-layer and bow-shock gradients.

The LATCH engineering $\operatorname{code}^{3}$ is based on the axisymmetric analogue for three-dimensional boundary layers and is used in many of the studies in this overview to compute the local boundary-layer edge properties, pertinent to parameters typically used in the determination of boundary-layer transition onset, as well as to compute the local heating levels. In the calculation of the local properties, the code uses the inviscid flowfield solution from LAURA and also incorporates an entropy-swallowing technique. The calculations are performed in a generalized body-fitted coordinate system and are based on solution of the integral momentum equation along streamlines. An approximate heating technique 9 for laminar and turbulent flows is incorporated in the procedure. Predictions based on these heating equations have been shown to yield good agreement with experimental ground- and flight-test data and with CFD predictions at planetary and earth-entry conditions (e.g. Refs. 3 and 9-11).

MINIVER $^{4}$ is a versatile engineering code that uses various well-known approximate heating methods, together with simplified flowfields and geometric shapes to model the vehicle. Postshock and local flow properties based on normal-shock or sharp-cone entropy conditions are determined in MINIVER through user selection of the various shock shape and pressure options. The calculations can be based on perfect-gas or equilibrium-air chemistry. AOA effects are simulated through the use of either an equivalent tangent cone or an approximate cross-flow option. The flow can be calculated for either two- or three-dimensional surfaces. However, the three-dimensional effects are available only through the use of the Mangler transformation for flat-plate to sharp-cone conditions. MINIVER has been used extensively as a preliminary design tool in government and industry and has been shown to be in good agreement with Shuttle orbiter data, other ground- and flight-test data in Refs. 12-14 as well as CFD calculations in Refs. 13 and 14. 


\section{Discussion}

In this section, aeroheating issues that can impact RLV design are reviewed. Observations are generally based on data from the published literature and the technical experience of the authors. The existing data illustrate the valuable database that can result when appropriate methods are employed. The issues that are addressed include boundary-layer transition, shock-shock interactions, low-density effects, uncertainties in material surface properties, and factors in design trajectory selection. A review of an integrated process to develop an aeroheating database for TPS design will also be presented. For any entry vehicle design, the heating level and load contribute to the TPS selection and sizing. During the TPS design phase, heating time histories are typically computed with engineering codes that have been benchmarked with a limited number of CFD cases and/or experimental ground-test data. Freestream conditions and vehicle geometry issues, as well as other factors can affect the predicted heating levels.

\section{A. Issues}

Transition Onset: The stability of the laminar boundary layer has been the topic of many studies (e.g. Refs. 15-22). The practical application of transition onset in the aeroheating/TPS design of entry vehicles has likewise been the focus of many studies (e.g. Refs. 23-31). A primary concern is that transition, with the associated increased heating levels, will occur during the high-heating portion of the entry trajectory with a potential negative impact on the TPS. However, we recognize the significant role trajectory tailoring ${ }^{31}$ can play in delaying transition onset for wingedand lifting-body entry vehicles. Early transition can be promoted due to surface roughness, but the manufacturing and processing departments at major aerospace firms have gained valuable experience in the control of surface roughness during the manufacturing process through the technology development programs for various X-vehicles. Surface roughness control technology is presumably more mature for ceramic tile systems than for metallic TPS.

Many of the early transition studies were limited by the lack of global measured data over the model. The twocolor phosphorus technique provides the flexibility to take measurements over a range of conditions such that a detailed map of transition onset can be generated. While more data are now available, the question remains as to how the data should be reduced and applied to flight conditions. The approach used by the experimentalists and computationalists in the $\mathrm{AB}$ at the $\mathrm{LaRC}$ is to define the local conditions at the location of transition onset in terms of the ratio of local momentum thickness Reynolds number to the local Mach number. This ratio will hereafter be referred to as the transition parameter. This parameter is one of many used in past studies (e.g. Ref. 30) to characterize transition onset and was the defining transition parameter used in the Shuttle orbiter design ${ }^{24}$. The uncertainty lies mainly in the selection of the appropriate value for this ratio on smooth and rough surfaces.

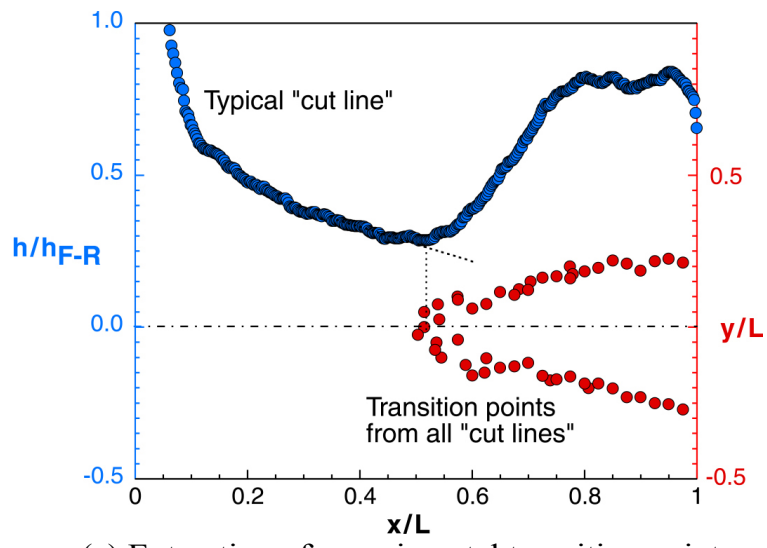

(a) Extraction of experimental transition points.

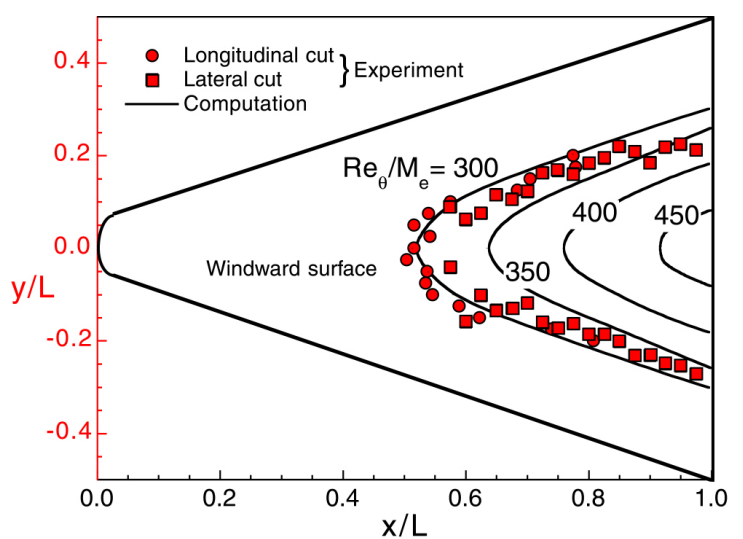

(b) Correlation with computed $\mathrm{Re}_{\theta} / \mathrm{M}_{\mathrm{e}}$.

Fig. 3 Determination of "smooth body" value of $\operatorname{Re}_{\theta} / M_{e}$ for $M=6, \alpha=40 \mathrm{deg}, \operatorname{Re}=4 \times 10^{6} / \mathrm{ft}$

To illustrate how the transition parameter has been applied by the $\mathrm{AB}$ researchers to ground- and flight-test conditions, a brief review of X-33 transition studies is presented. In Ref. 6, a smooth body value of the transition parameter was defined; effects of discrete trips along the centerline on transition were quantified, and the application of these data to a trajectory corridor was demonstrated. In Fig. 3(a), the procedure for determining the transition location is shown. For selected cut lines on the heating images, transition is inferred from the location where the heating initially diverges from the laminar trend (e.g. $\mathrm{x} / \mathrm{L} \sim 0.5$ in Fig. 3(a)). Evaluating data at several test cuts of the heating image allows the transition data shown in Fig. 3(b) to be obtained. A match of these experimental data is 
then obtained by computing different values of the transition parameter and comparing them to the measured data. For this configuration, a good comparison is shown for a transition parameter value of 300 . When all test conditions of Reynolds number and AOA were considered, there was only about a ten percent variation in the value that was observed.

In Ref. 7, surface roughness effects on transition onset were investigated using two forms, discrete and distributed (wavy wall) roughness, at several locations on the vehicle. In relation to a flight vehicle, discrete roughness elements might represent protruding gap fillers or the raised corner of a metallic panel. The distributed roughness elements can be thought of as the equivalent roughness values assigned to gaps, steps and tile surface conditions for a ceramic tile system or bowed panels for a metallic system. The discrete and distributed roughness designs investigated are shown in Fig. 4. A typical discrete element is shown in Fig. 4(a) along with the various steps heights employed in the study. Figure 4(b) illustrates a layout of the elements along the centerline and at three attachment lines for 20-, 30- and 40-deg. AOA. Figure 5 demonstrates the advantage of combining experimental and computational tools in an investigation and the insight that can be gained. The results of the computational tools are seen in Fig. 5 in the placement of the series of fiducial marks shown on the model noting the 20-, 30- or 40degree attachment lines. The fiducial marks were located on the model based on calculated results from LATCH. The experimental and computational results used to determine streamline paths and ultimately an attachment line are shown to be in good agreement. The comparison ${ }^{7}$ shown in the figure is for the location of the attachment line at 30 deg. as depicted by oil flow and computational results. Certainly it is recognized that the agreement of viscous oilflow results and inviscid computed streamline results could be questioned, but no further discussion was offered in the reference. Figure 4(c) shows the distributed (wavy wall) roughness patterns used in the test to simulate the bowed metallic panels. The analysis of Ref. 32 for the X-33 demonstrator showed that outward bowing of the metallic panels would occur due to thermal gradients and that heights as large as 0.25 inches could be expected for flight conditions.

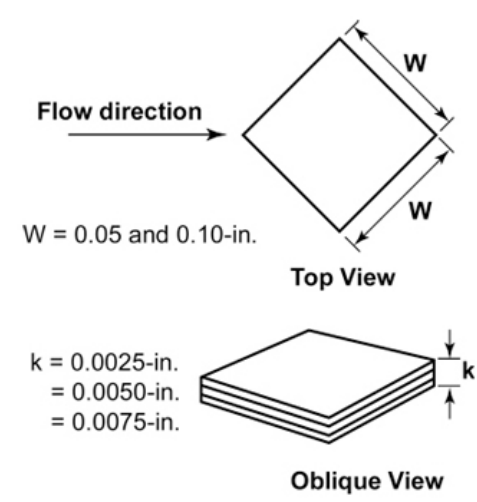

(a) Trips showing orientation, width, and height.

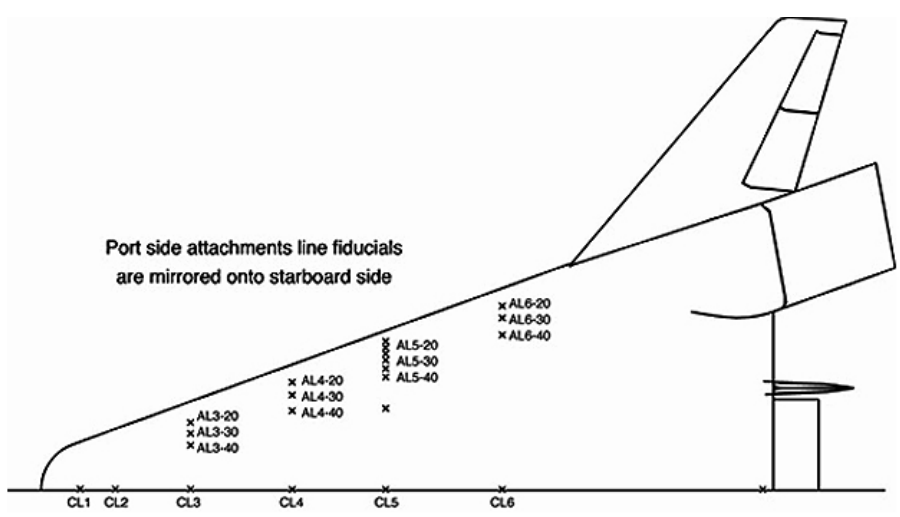

(b)Trip locations and fiducial marks

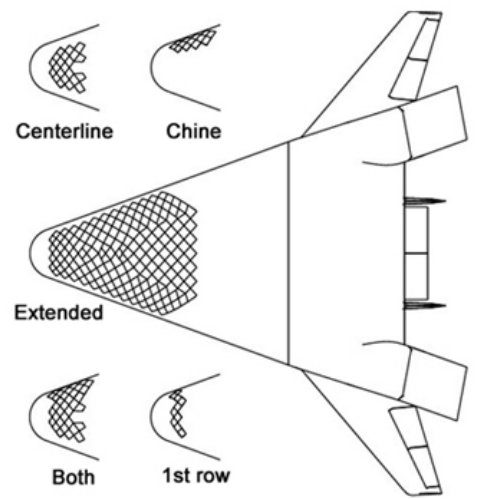

(c) Various bowed-panel configurations.

Fig. 4 Surface roughness. 


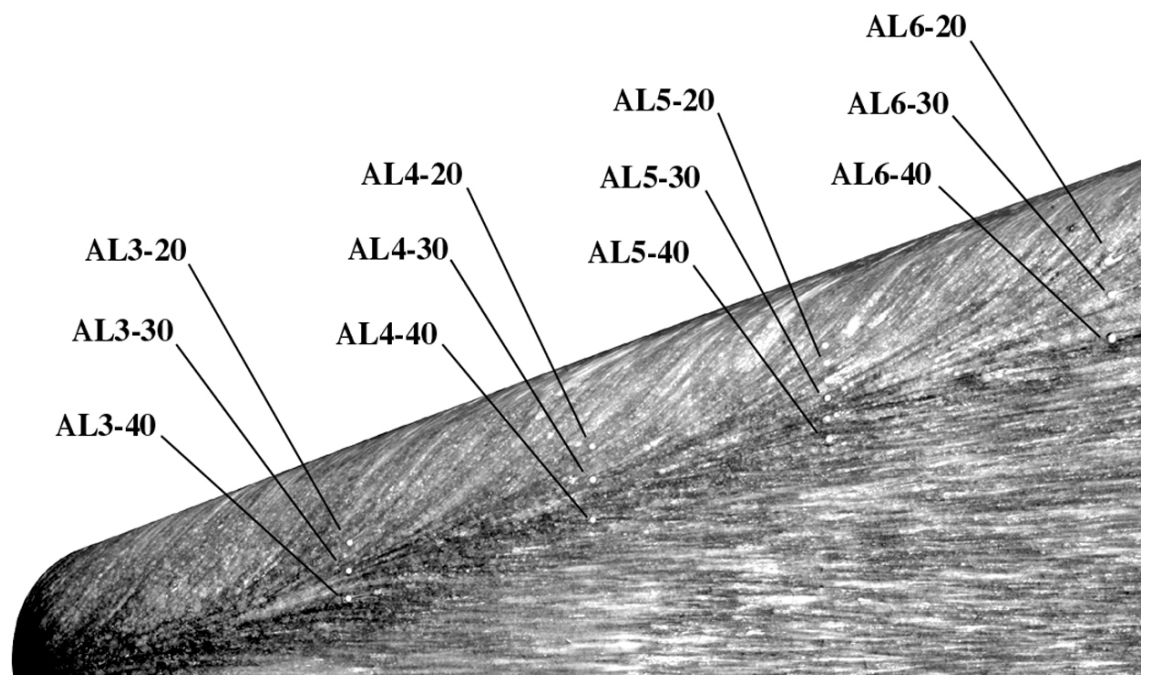

Fig. 5 Surface streamlines showing attachment line location for $\alpha=\mathbf{3 0} \mathrm{deg}$

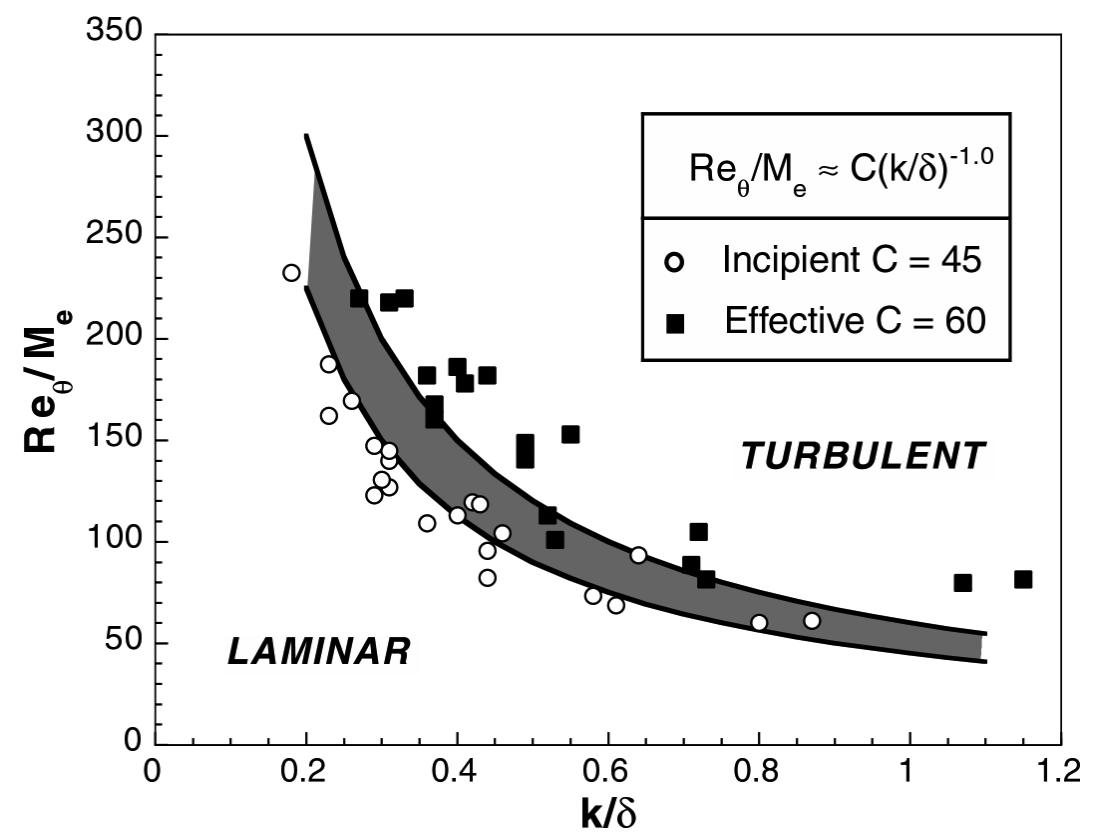

Fig. 6 Roughness transition correlation.

For a range of Reynolds numbers at a given AOA in the Ref. 7 study, trip locations were recorded for the maximum Reynolds number at which laminar flow was maintained downstream of the trip (referred to as incipient) and for the minimum Reynolds number at which transition occurred at the trip location (effective). It should be noted that the terms "incipient" and "effective" are used here as defined in Shuttle orbiter transition studies ${ }^{24}$. At these trip locations, the LATCH code was used to compute boundary-layer edge properties that were then used to determine the values of the transition parameter. The resulting formulation is presented in Fig. 6. (Note that these results are also presented in Ref. 6.) The horizontal axis is defined as a ratio of the step height to the boundary-layer thickness. Below the incipient curve, the flow is laminar and above the effective curve, the flow is turbulent.

The results of Fig. 6 have two important uses. One use is the determination of allowable roughness heights for which the flow is expected to remain laminar. For example, if the value of the transition parameter is selected as 250 , then the ratio of boundary-layer to roughness height is 0.2 as obtained from the incipient curve. The LATCH 
code can be used to map the boundary-layer thickness over the body at a given flight condition, and the corresponding allowable surface-roughness heights determined. These heights can be compared to allowable manufacturing tolerances to assess whether the surface roughness of the "as built" vehicle is likely to trigger transition prematurely. The second potential use of the formulation presented in Fig. 6 is the incorporation of the transition parameter in the development of a unique analytical method ${ }^{6}$ that enables the prediction of transition on the vehicle over the range of altitudes, velocities, and angles of attack pertinent to the development of an entry trajectory profile. This approach is shown conceptually in Fig. 7 for a given value of the transition parameter and body location. The analytical tool can be incorporated in an entry trajectory simulation to shape trajectories such that transition onset is delayed and represents a major contribution to the aeroheating design process for an RLV. The analytical technique that was conceived in Ref. 6 utilized LATCH predictions to map the transition surface. A similar analytical result using the MINIVER code was developed in Ref. 31 and presents a more viable engineering approach for implementing the method within trajectory simulations.

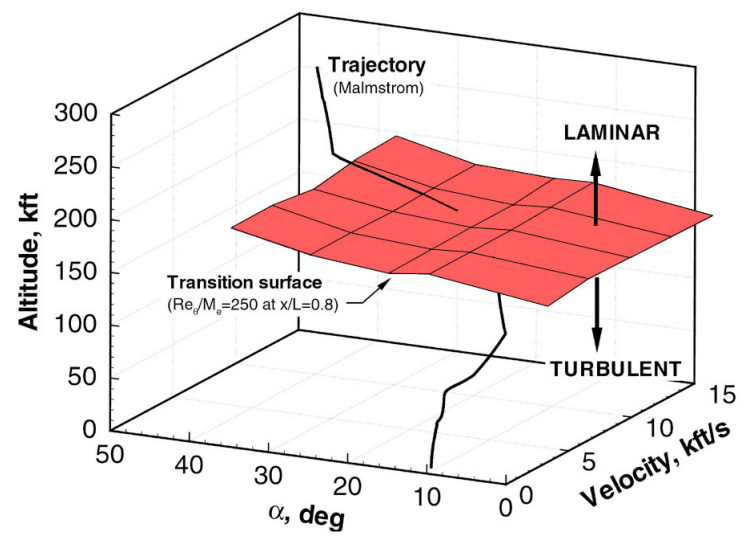

Fig 7 Transition surface.

Several investigators have suggested that boundary layers are more sensitive to being tripped to turbulent flow for a roughness element located along an attachment line than for an element located along the centerline. However, it was found that transition data measured with discrete trips along the attachment line were bounded by the results for the centerline trips shown in Fig. 6. Thus, at least for the X-33 vehicle, the attachment-line roughness elements did not exhibit a greater potential for tripping the boundary layer than the centerline elements. Finally, distributed roughness was shown to be less effective in promoting transition than the discrete trips, but it was noted that a larger portion of the body was influenced. A summary ${ }^{7}$ of the X-33 transition data for both smooth and rough surfaces based on the transition parameter versus the freestream Reynolds number is presented in Fig. 8.

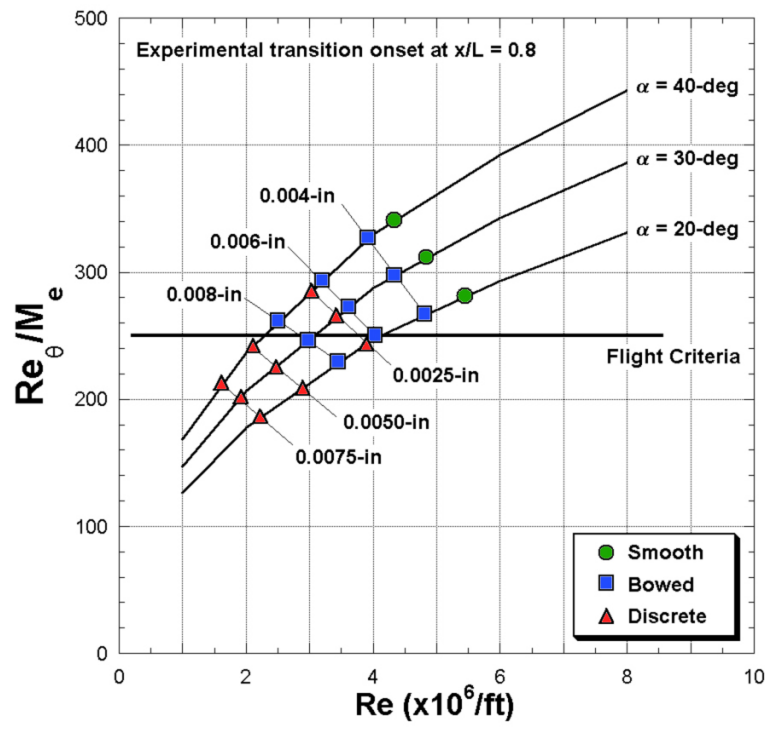

Fig. 8 Comparison of wind-tunnel results of smooth, bowed, and discrete trip tests to flight criteria 
Shock-Shock Interaction: Shock-shock interactions represent a region of complex flows and, for the bow-shock wing-shock region, the interaction location is likely to represent the highest heating area on winged entry vehicles. This region was the focus point of the recent Shuttle Columbia investigation ${ }^{33,34}$. This bow-shock wing-shock flow region can also produce some interesting experimental challenges in data interpretation. For instance, the planform schlieren image given in Fig. 9(a) for the X-34 mode $^{35}$ appears to show the bow shock interacting with the wing leading edge at an outboard location. However, this experimental result is not confirmed by oil flows or experimental heating images (Figs. 9(b) and 9(c) respectively). The oil flows and heating images show the shock interaction on the wing to occur at a more inboard location. This discrepancy was eventually resolved with further investigation, aided significantly by the examination of the CFD solution ${ }^{36}$ shown in Fig. 9(d). From the figure, the Mach contours show two results -- first, the false location that would be inferred from the schlieren planform image, and second the computed shock interaction location confirmed by the oil flow and heating data.

A somewhat more perplexing result was obtained in the final heating tests ${ }^{37}$ of the X-33 model. As the X-33 investigation matured, the vehicle configuration evolved. One change was that the body flaps were lengthened to improve vehicle control. It is also important to note that the X-33 body flaps are located outboard to either side of the centerline. Tests on the modified configuration showed an unexpected heating increase (Fig. 10(a)) downstream of the flow separation/reattachment location. The cause of the heating increase was not immediately obvious and, for a time, thought to be an anomaly in the experimental process. Oil flow tests (Fig. 10(b)) also showed evidence of a disturbance in this area, thus dispelling this notion. Further experimental investigation aided by CFD results ${ }^{38}$ led to the conclusion that the cause of the disturbance was the close proximity of the deflected flap shock to the windward bow shock from the nose. The shock interactions produce an expansion fan intersecting the body flap. This effect is apparent in the predicted flowfield density contours and body-flap surface pressures shown in Figs. 10 (c) and 10(d) respectively. The CFD solutions ${ }^{38,39}$ also showed the expected decrease in the flap effectiveness as well as a heating increase in the region shown by the experimental heating results.
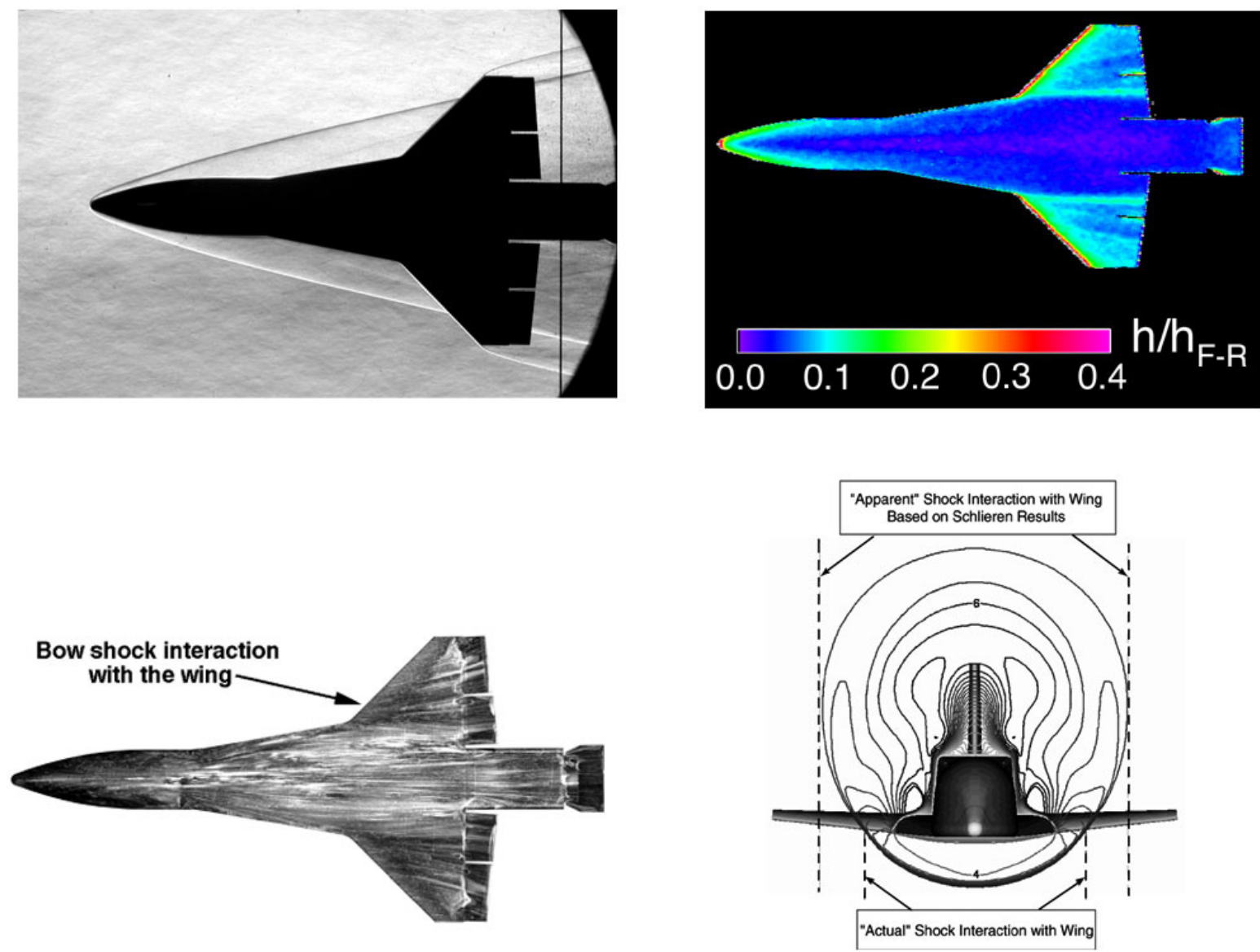

Fig. 9 X-34 wing shock interaction at $M=6$ and $\alpha=15$ deg. 
Flow Separation/Boundary Layer Reattachment: Boundary-layer separation and reattachment must be understood adequately to ensure a successful vehicle design because they can affect the aerodynamics and local heating. Data illustrating these flow effects are presented not only to note that these issues could seriously impact the vehicle design, but also to again demonstrate the wealth of information available to the investigator through use of the experimental technique. Figure 11 shows the influence of flow separation/reattachment on deflected control surfaces for the X-38 vehicle ${ }^{40}$. The heating data (Figs. 11(a-c)) ahead of the body flap and the separation region are essentially independent of Reynolds number suggesting laminar flow. However, on the body flaps the heating levels are seen from these three figures to increase with Reynolds number indicating non-laminar flow. The investigation also included an upstream trip to ensure turbulent flow on the deflected flap. These data, presented in Fig. 11(d), show higher forebody heating and a relatively large decrease in the separation distance. However, the body flap heating is lower than shown for the untripped data in Fig. 11(c). It should be noted that heating on body flap in Fig. 11(c) is off-scale high. Thus, it appears that forebody turbulence reduces the downstream flap heating, and thus forebody turbulence may not represent the appropriate design condition for deflected body flaps. Similar experimental results were also presented in Ref. 37 for heating on the X-33 deflected body flaps.

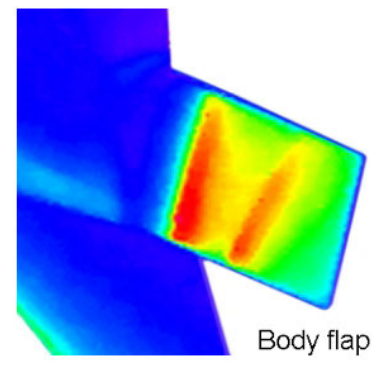

(a) Heating image.

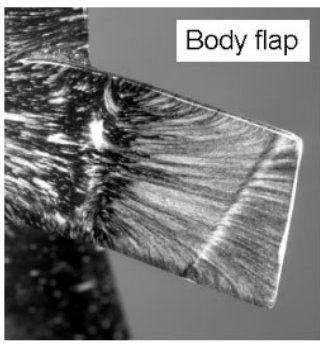

(b)Oil flow.

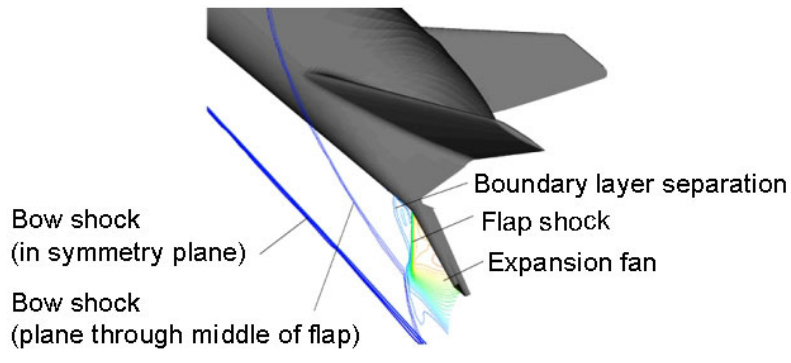

(c) Density contours.

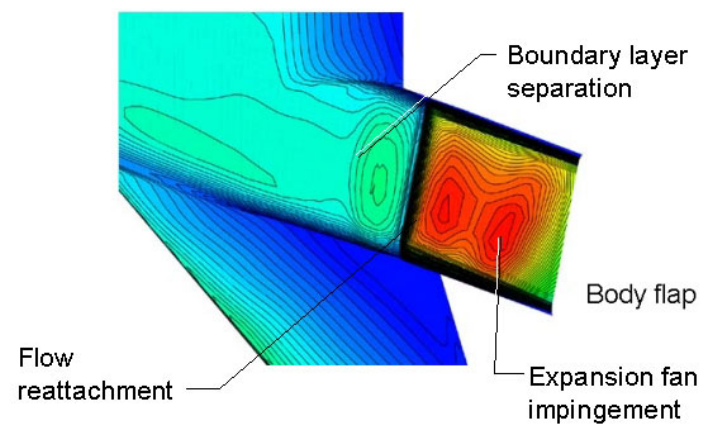

(d) Body flap pressure contours.

Fig. 10 Expansion fan impingement on $X-33$ body flap at $M_{\infty}=6$, $\alpha=40 \mathrm{deg}, \delta_{\mathrm{bf}}=20 \mathrm{deg}, \operatorname{Re}=4 \times 10^{6} / \mathrm{ft}$

Vehicle OML Design/Shaping: In the preliminary design phase of many proposed vehicles, the lines are often rapidly generated. The associated experimental or computational studies based on grids from early lofts sometimes demonstrate unexpected vehicle flow characteristics. Such was the case for a study of a proposed Assured Crew Return Vehicle (ACRV) documented in Ref. 41. In Figs. 12(a) and 12(b), oil-flow and heating data show nonuniform flow at fairly low angle of attack emanating from the change in planform contour. These flow characteristics were observed for angles of attack of less than approximately $25 \mathrm{deg}$. The streamlines were more uniform in behavior and were shown to turn outward at angles of attack greater than approximately $40 \mathrm{deg}$. (not shown herein). If the investigation had continued, there were plans to pursue a slight planform change to ensure more uniform flow over a larger AOA range as well as to reduce the high heating region. 

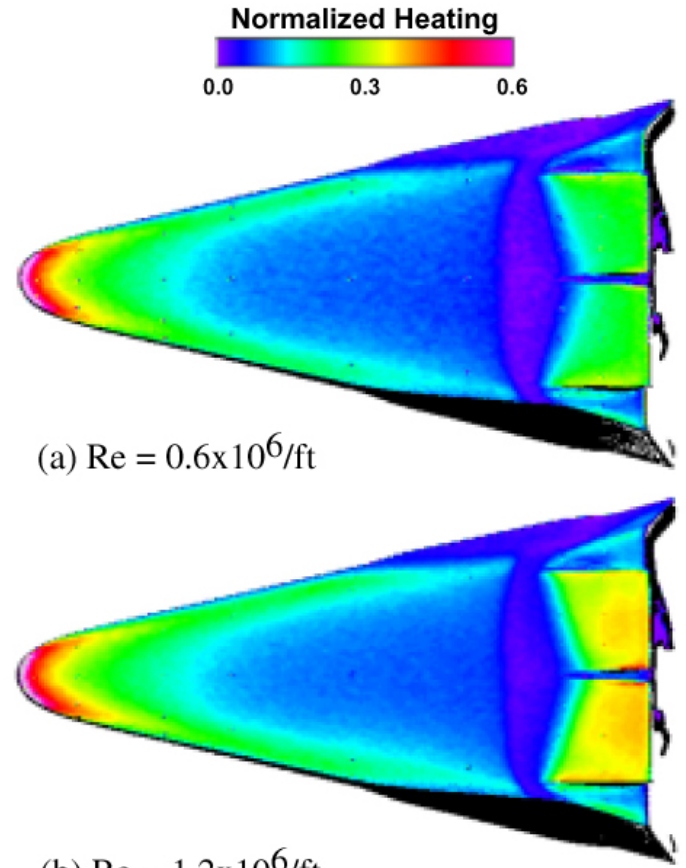

(b) $\operatorname{Re}=1.2 \times 10^{6} / \mathrm{ft}$
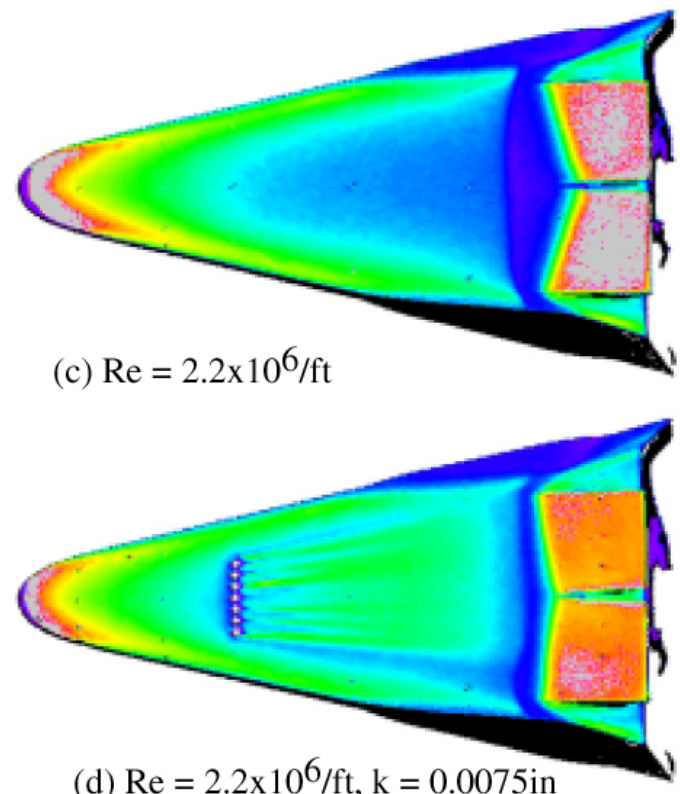

Fig. 11 X-38 boundary-layer separation/reattachment at $\operatorname{Mach}=10, \alpha=40, \delta_{b f}=25$ deg.

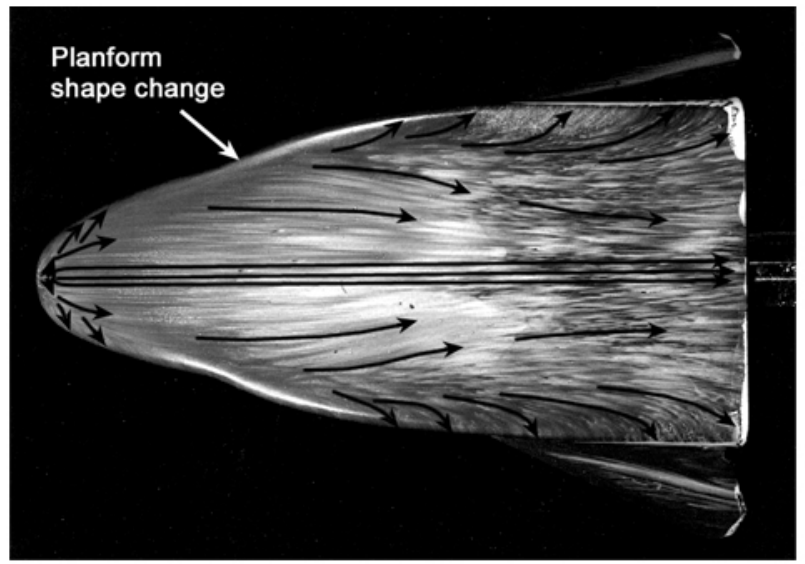

(a) Oil flow patterns

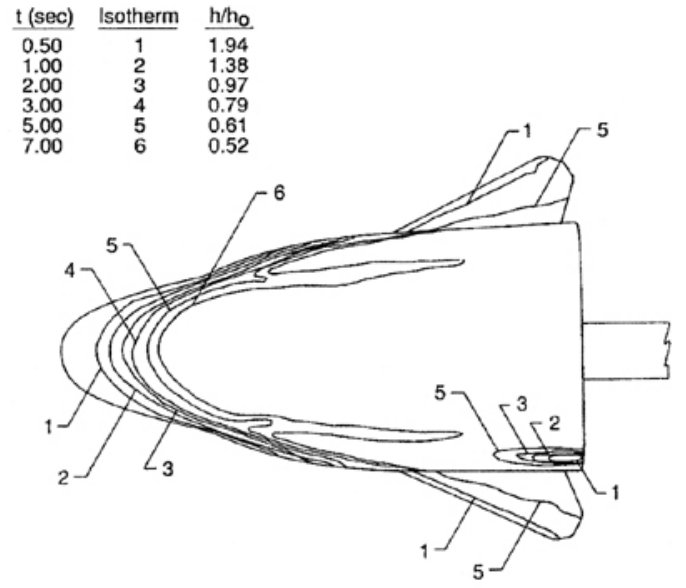

(b) Heating contours

Fig. 12 Effects of planform shaping on surface data.

A more recent design study demonstrated a possible problem inherent to winged entry-vehicle concepts that must carry large propellant tanks within the fuselage. Vehicle designers, in an attempt to steer away from the wing passing through the structure and posing additional problems of how to deal with the internal tanks, opted to pass the wing structure under the fuselage. The implication of a rather large "bump" on the windward surface of a hypersonic vehicle and the potential for transition may not have been intuitive to the designers. Possibly, the challenge of integrating the wing structure and the dilemma of dealing with the internal tank packaging were greater problems to overcome. Nevertheless, the resulting bump on the windside became a major concern for the manufacturer. The effective roughness of the bump was found to be larger than many of the roughness conditions noted to cause premature transition on the Shuttle ${ }^{23}$. Figure 13 illustrates the effect of the bump on the local and downstream 
surface properties, namely the heating rates and surface pressure. Figure 13(a) is a heating image of the windward surface (unpublished measured results obtained by Dr. Scott Holland and Michael DiFulvio of the AB) and shows the dramatic effect the bump has on the downstream heating. Figures 13(b) and 13(c) are comparisons of the predicted heating rates and pressures at and downstream of the bump location. The comparisons are based on predicted results using the LATCH and MINIVER codes with heating increases noted over pre-bump levels to be as large as a factor of 5. A study (unpublished) was performed to assess the effect of the bump and the cost (in dollars and weight) to replace and resize the TPS to accommodate higher heating associated with early transition over the majority of the vehicle acreage. An alternative approach considered was fairing the bump forward, thus mitigating a significant forward facing step on the windside, but the program was halted prior to completion of this aspect of the trade study.

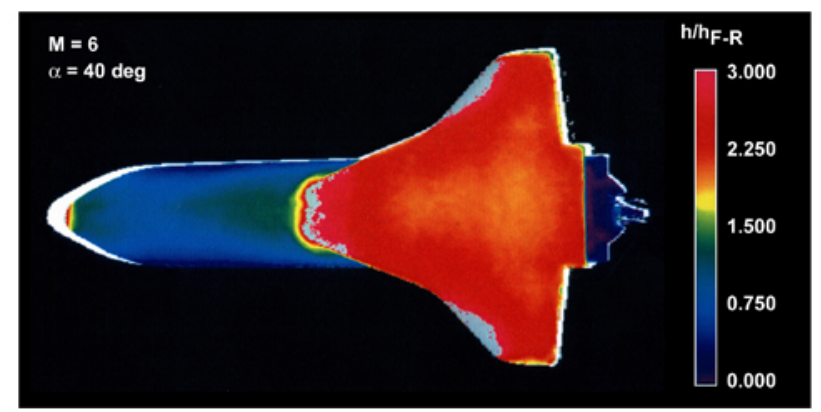

(a) Heating image

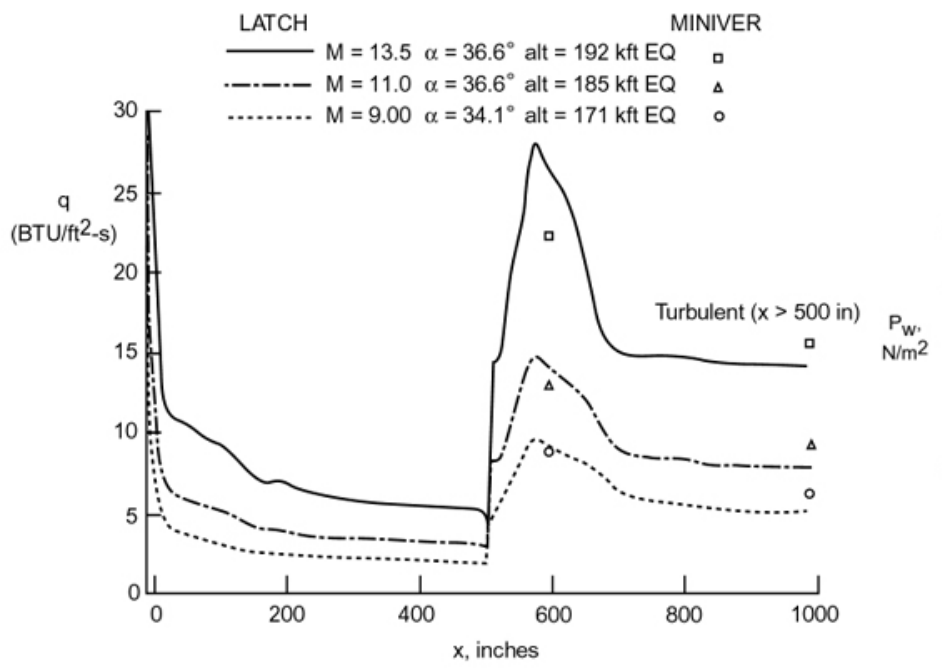

(b) Predicted heating rates

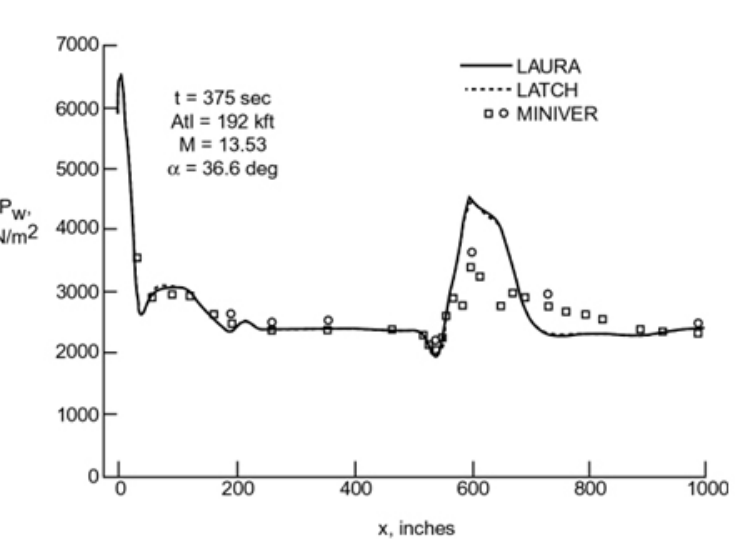

(c) Predicted pressure

Fig. 13 Effect of bump on windward centerline surface data.

Further examples of experimental and/or computational data driving the modification of a vehicle OML have been encountered in a recent study. The entry vehicle, as designed, employs a tile system to protect the wing leading edge. The relatively small wing-leading-edge radius for the initial design led to computed leading-edge heating levels that exceed the current TPS capability. In a very fast paced effort, a wing redesign was initiated: several wing designs were lofted; grids were developed; and solutions obtained in a trade study to find an acceptable design. Figure 14 shows the maturation of the trade study relating to the shock structure as an acceptable wing evolved, and Fig. 15 presents the predicted heating rates for selected wing configurations. In Fig. 14, the OML was modified by increasing the strake angle outward as well as increasing the leading edge radius and the wing sweep. The effect of these changes was to diminish the strength of the shock interaction on the wing. The results shown in Fig. 15 clearly indicate the dramatic reduction in heating levels at the shock intersection region. While it is recognized that the bowshock wing-shock intersection usually represents the region of highest heating on the wing, the wing tip can also 
represent a potential region of high heating and must be monitored through any redesign of the wing. The shaping of the nose and forebody of the vehicle was likewise found to be a problem. The original nose geometry had to reshaped because it was shown by CFD analysis (Fig. 16) that, for the high AOA, the smaller nose was producing a region of rapidly expanding flow (similar to a corner on a capsule) and consequently increased heating levels. Note that the design heating rates were initially computed with classical boundary-layer assumptions using engineering techniques that did not account for viscous effects.

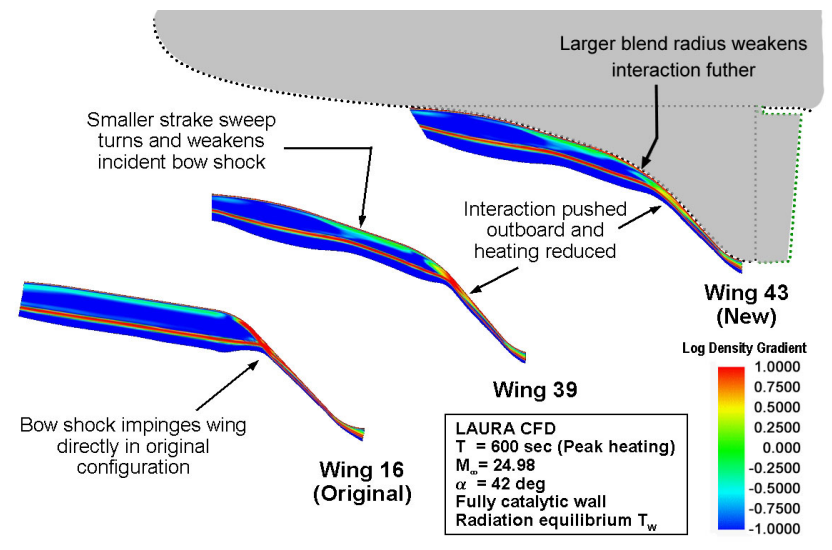

Fig. 14 Wing parametric study and redesign.

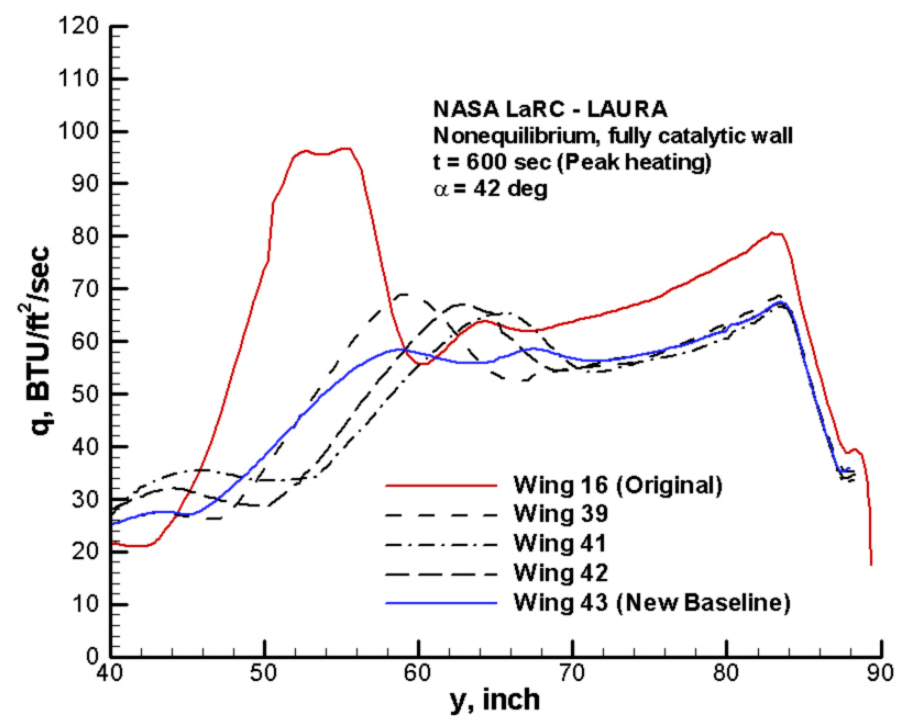

Fig. 15 Wing leading-edge peak heating.

Low-Density Effects (viscous interaction): The influence of low-density conditions or small nose radii on the computed heating rates has been documented in the literature (e.g. Refs. 42 and 43). In these situations, boundarylayer assumptions fail because the shock layer becomes increasingly viscous, and the boundary layer cannot be assumed to be a thin region near the body surface. Computational and experimental results from Refs. 42 and 43 are shown in Figs. 17(a) and 17(b). The figures demonstrate that, for decreasing nose radii or density, the computed or measured heating rates exceed the value predicted using boundary-layer assumptions. Specifically, the results of an engineering code ${ }^{9}$ that couples the inviscid and viscous flow are shown in Fig. 17(a) to be in relatively good agreement with the equilibrium prediction of Ref. 42 over the range of radii. However, the differences in the classical boundary-layer predictions and those of Ref. 42 grow dramatically with decreasing values of the radius. In Fig. 17(b), the experimental data from Ref. 43 are obtained over a range of Mach number, test gases and normalshock density ratios. Also, a stagnation-heating correlation ${ }^{44}$ is shown. The results of the experimental data as well 
as of the correlation demonstrate that, for decreasing density, classical boundary-layer assumptions do not predict the correct heating levels. While the Shuttle orbiter does encounter a high degree of nonequilibrium flow, thick viscous layers were not a driver in the Shuttle design analysis, and boundary-layer methods were used successfully as the design tool. However, during a recent investigation of a small vehicle configuration, low-density effects were again shown to have a significant impact on heating rate levels (Fig. 18) computed with engineering and CFD codes. The figure presents predicted heating rates based on engineering codes using different boundary-layer assumptions as well as showing comparisons with CFD results. Initial design heating estimates were based on classical boundary-layer assumptions. These results are lower by approximately $35 \%$ compared to the results generated by VAB using the low-density model in MINIVER. The results from a wide range of other codes are shown to agree well with the MINIVER low-density model results. Certainly, the lower rates based on boundary-layer assumptions would likely have led to an under-designed TPS.

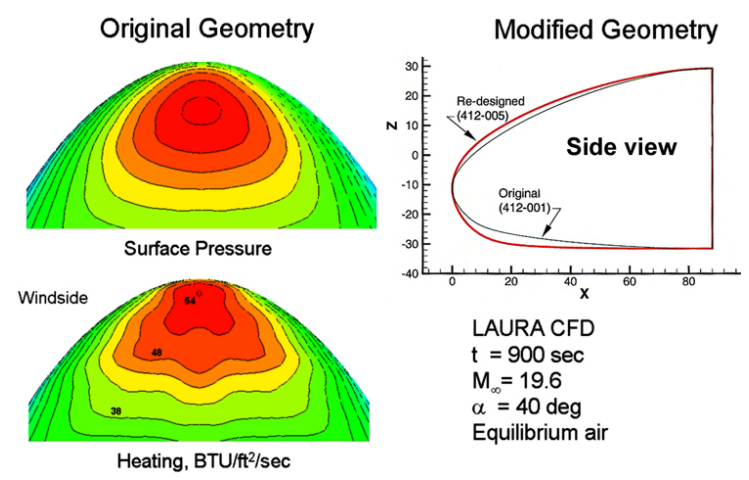

Fig. 16 Nose redesign.

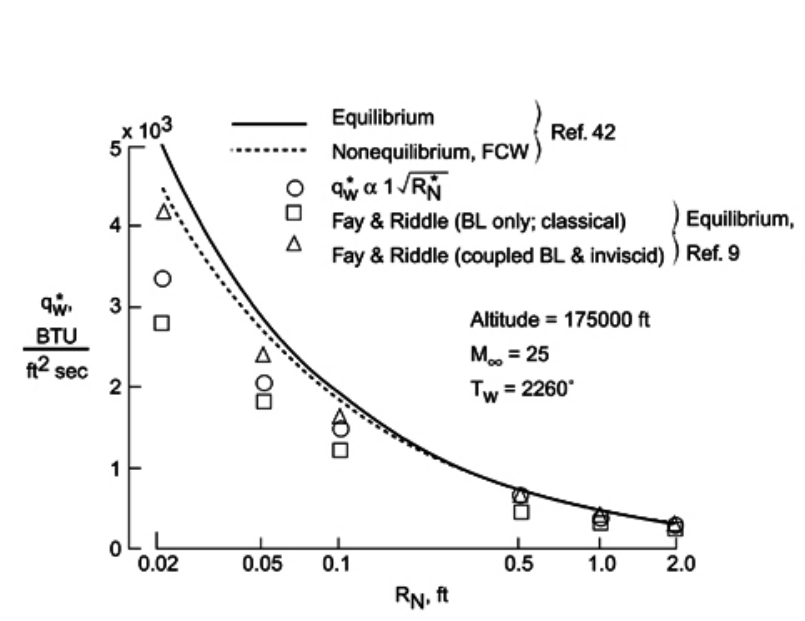

(a) Radius effect

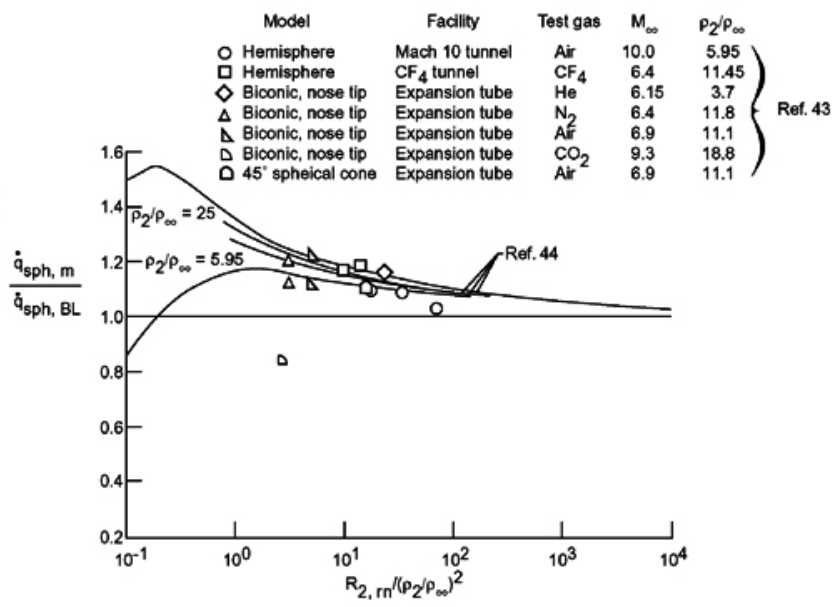

(b) Density effect

Fig. 17 Viscous effects on classic boundary-layer methodology. 

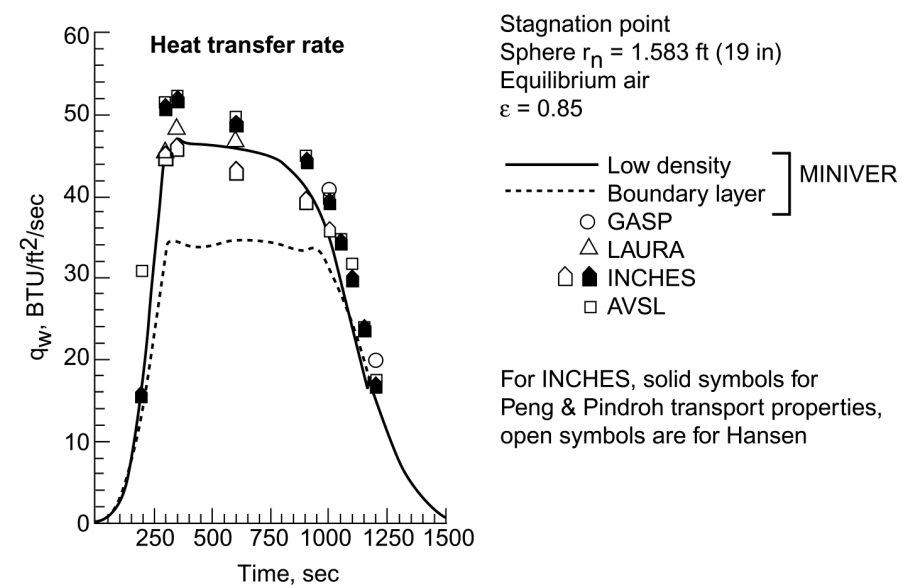

For INCHES, solid symbols for Peng \& Pindroh transport properties, open symbols are for Hansen

Fig. 18 Viscous effects on heating predictions.

Material Surface Property Uncertainties: Two surface properties that influence aeroheating predictions and/or TPS design are the emissivity and surface recombination coefficient. The energy radiated from the surface is directly proportional to the emissivity thereby reducing the net heat load into the TPS. The recombination coefficient is a measure of the material capability to inhibit the recombination of atoms at the surface and thus reduce the surface heating in a nonequilibrium flowfield. The material that has the lowest coefficient will experience the lowest diffusional heating rate. A desirable combination of properties would be a high emissivity and low recombination coefficient. In the recent Shuttle accident investigation, the question "What are the values of emissivity and catalycity for the coating on the Shuttle carbon-carbon leading edge?" received the answer "The material is very much like Reaction Cured Glass (RCG)". RCG has a glassy appearance and is the coating used on the windward surface tiles installed on the Space Shuttle orbiter. The RCG values of the recombination coefficient and emissivity from Ref. 45 were used in the calculations during the accident investigation and are presented in Figs. 19 and 20. However, the return to flight activity has again focused attention on the wing-leading-edge calculations. Recent discussions have produced an understanding that the appropriate recombination coefficients for the carbon-carbon coating are actually listed as C-CAT in Ref. 45 and are presented in Fig. 19. However, the corresponding emissivity values from that reference are not shown on Fig. 20. Rather the temperature dependent emissivity values given in Ref. 46 are presented in Fig. 20. It was stated in Ref. 46 that this set of emissivity values were used in the thermal analysis for the radiometer located on the wing spar. Since the emissivity values in Ref. 46 were used in the data reduction of the radiometer data to infer wing temperature and heating rates at a body location, then it would seem appropriate that the CFD calculations should use the same emissivity data. Figure 21 presents the predicted spanwise nondimensional maximum heating rates along the wing leading edge at the STS-2 freestream conditions noted on the figure. The calculations are based on two sets of properties for the recombination coefficient and the emissivity. One heating calculation is based on RCG properties, and the other uses the C-CAT recombination coefficient from Ref. 45 and the emissivity values documented in Ref. 46. The differences in the two heating predictions are as large as $13 \%$ in the spanwise heating distributions. At the first heating peak that represents the wing-shock bow-shock intersection, the discrepancy in the two results is about $11 \%$. Note also that the heating distribution along the wing leading edge not only shows a peak at the bow-shock wing-shock intersection location but also has a second peak at the wing tip, similar to the results noted previously. It is also of interest to note from the figure that the heating rates inferred from radiometer measurements and the peak predicted values are not located at the same spanwise location. Also, the radiometer $\mathrm{x}, \mathrm{z}$ location is not the same as any $\mathrm{x}, \mathrm{z}$ location defining the peak heating-rate distribution lines presented in Fig. 21. The radiometers were installed to measure a peak heating at a location on the wing leading edge based on pre-flight wind-tunnel tests at relatively low Mach number conditions characterized by non-reacting flow. The highly reactive flow at flight conditions has a shock stand-off distance that is much closer to the body as well as a higher shock density ratio than at the ground-test conditions. Consequently the wing-shock bow-shock intersection occurs more inboard on the wing leading edge than the ground-test results would indicate. Table 1 presents the predicted heating results at the body point corresponding to the radiometer measurement ratioed to the flight-inferred measurement ${ }^{47}$. A significant difference in the predicted and inferred measured values is noted. Again, the location of the radiometer measurement does not coincide with the locations of the peak heating distribution shown in Fig. 21. There are many questions that can be raised based on the results shown in the figure 
and table, but they are beyond the scope of this paper. Presently, there is a substantial effort to produce CFD results using very fine grids, and also a planned experimental program to measure the Shuttle wing-leading-edge heating rates over a wide range of Mach numbers and gas chemistry conditions. Hopefully, these two investigations will resolve the problem. However, the results in Fig. 21 indicate that an effort clearly needs to be made to establish appropriate surface properties for the current Shuttle analysis and for any future vehicle design.

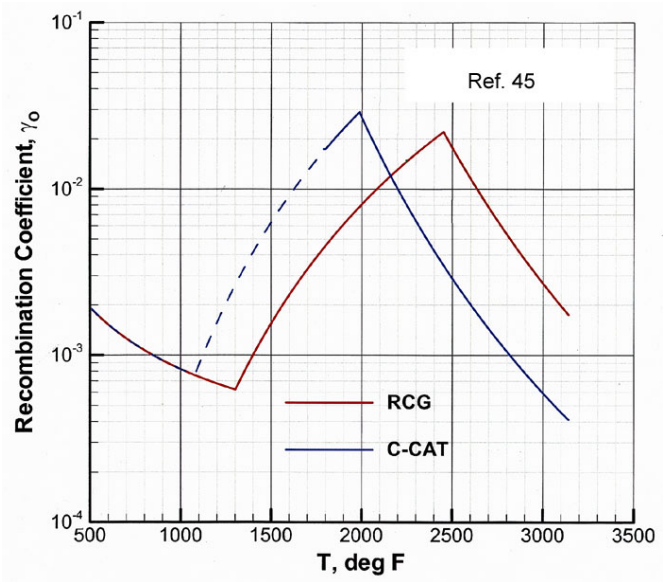

Fig. 19 Temperature dependent recombination coefficients for two coatings

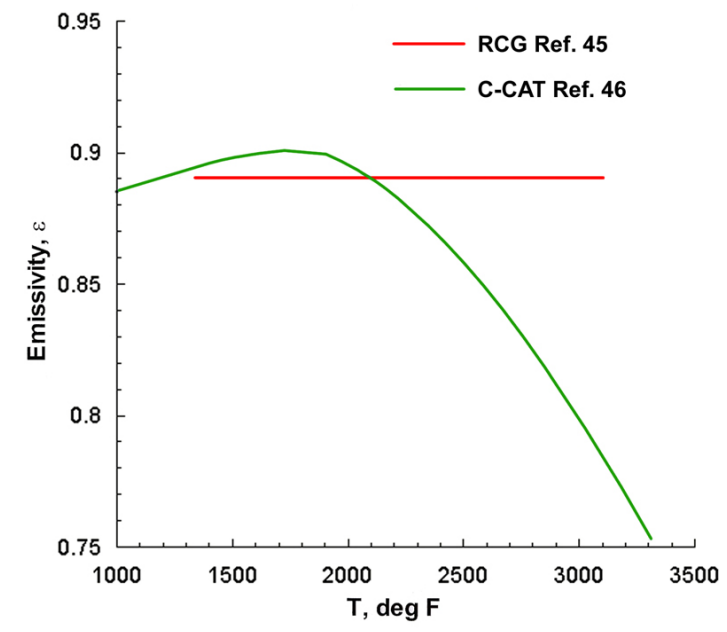

Fig. 20 Temperature dependent emissivity for two coatings.

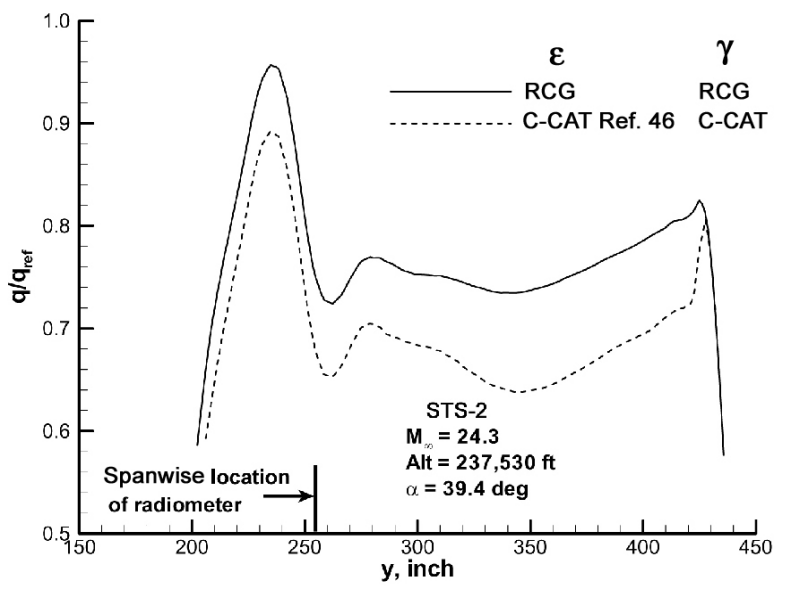

Fig. 21 Spanwise distribution of predicted peak heating rates along wing leading edge. 


\section{Table 1. Comparison of predicted to inferred measured heating at radiometer location}

\begin{tabular}{c|c}
\hline \hline $\mathrm{q}_{\mathrm{RCG}} / \mathrm{q}_{\text {measured }}$ & 0.59 \\
\hline $\mathrm{q}_{\mathrm{C}-\mathrm{CAT}} / \mathrm{q}_{\text {measured }}$ & 0.53
\end{tabular}

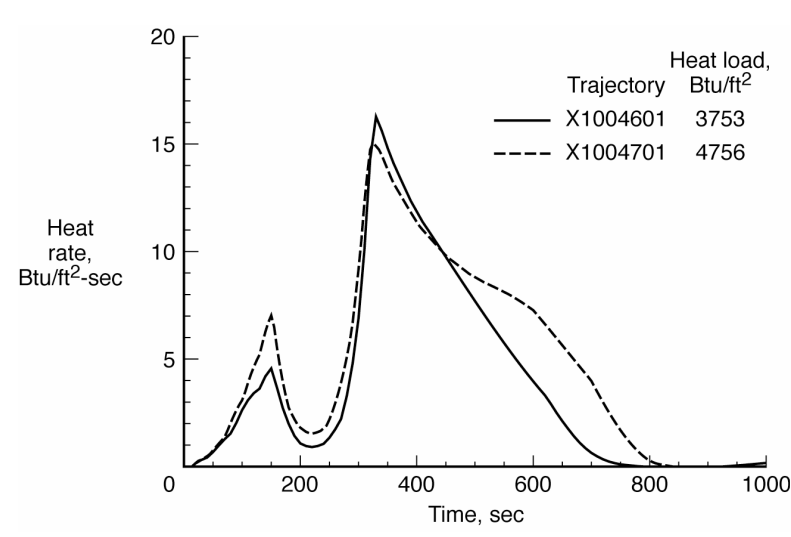

(a) Cold-wall reference heating-rate time histories

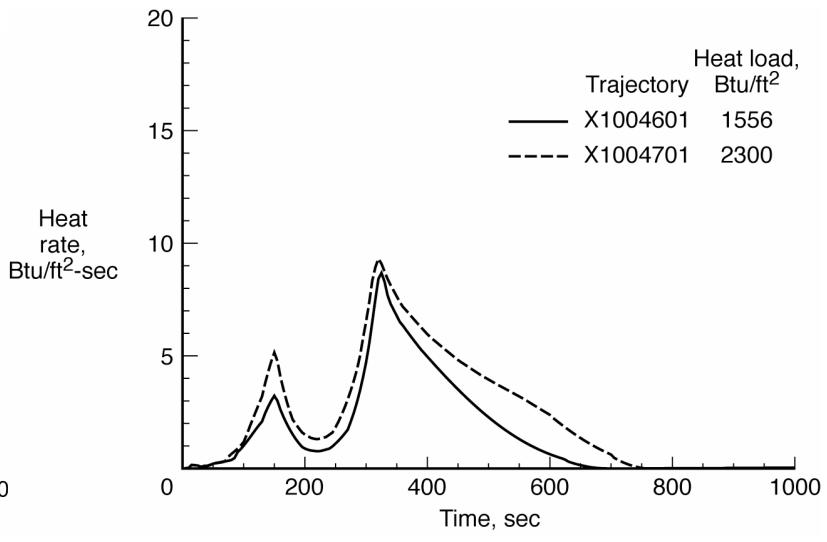

(b) Hot-wall reference heating-rate time histories

Fig. 22 X-34 design heating trajectory selection.

Design Trajectory Selection/Tailoring: The development of an aeroheating database for TPS selection and sizing requires knowledge of the altitude, velocity and attitude that a vehicle will encounter along its entry corridor. For the $\mathrm{X}-34$, members from the $\mathrm{AB}$ and $\mathrm{VAB}$ branches at LaRC were responsible for providing the aeroheating environments ${ }^{14}$ necessary for the acreage TPS design. A trajectory was provided to LaRC, and computational efforts commenced. As the analysis proceeded, the LaRC team observed that the selected trajectory did not adequately represent the worst case in terms of peak heating rate or heat load for predicted hot-wall conditions (ratio of computed wall enthalpy to total enthalpy). The selection of the trajectory with the highest heating rate was evidently based on cold-wall conditions (the same ratio, but the wall enthalpy is based on $0 \mathrm{deg}$. R). For an analysis of an entry at orbital velocities (high-enthalpy flow), the wall condition should have negligible impact the on the trajectory selection, but for a trajectory profile with the peak Mach number of only 7 (low-enthalpy flow), the wall condition can make considerable difference. (A similar situation was encountered in the recent X-43A Mach 7 Hyper-X thermal design.) The differences in heating rates and loads are shown in Figs. 22(a) and 22(b) for cold- and hot-wall conditions $^{14}$ respectively. Because time was critical and the analysis could not be restarted, a risk assessment was conducted with regard to the adequacy of the resulting TPS acreage design. The following assessments were made. Since the peak heating rates for the two time histories presented in Fig. 22(b) are about the same, the blanket material selection was not affected by the use of either trajectory. A thermal analysis showed that the TPS design thicknesses had adequate margin if the higher heat-load trajectory had been selected for acreage TPS design.

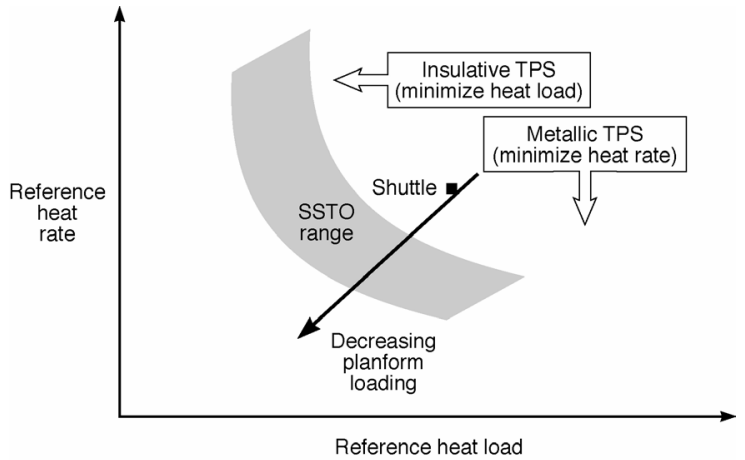

Fig. 23 Trajectories tailored to the TPS characteristics. 


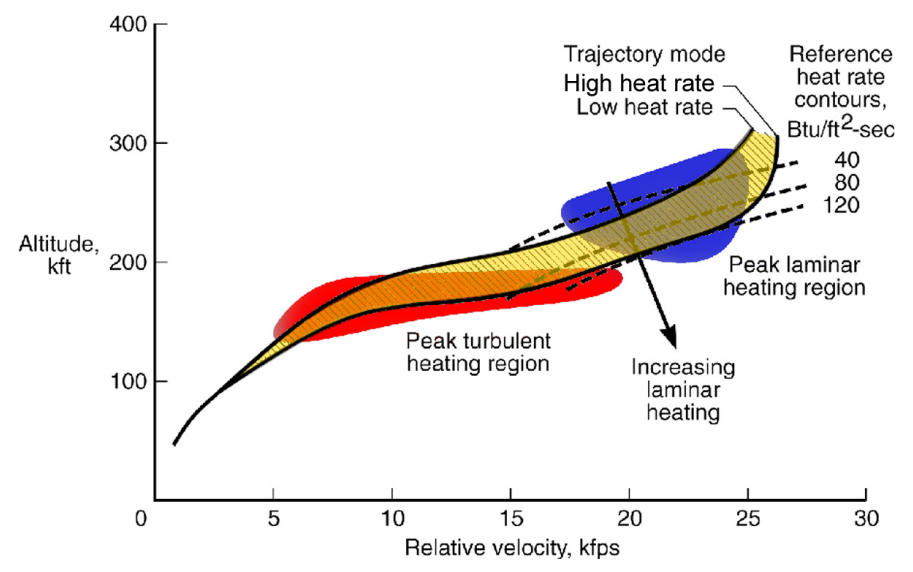

Fig. 24 Trajectory envelope for TPS characteristics.

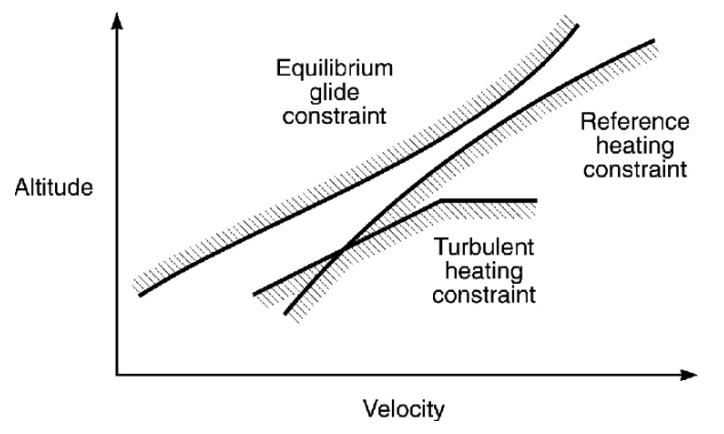

Fig. 25 Entry trajectory corridor for heating constraints.

When NASA first started looking at winged entry vehicles in the early 60 s, the typical approach was to determine the design trajectory first and then design the TPS based on that profile. The advent of winged space transportation systems with relatively good aerodynamic performance characteristics provided the flexibility to develop trajectories over a broad range of altitude-velocity conditions. Several investigations ${ }^{48-50}$ were conducted that demonstrated the effect of turbulence on different TPS concepts; the requirements for ceramic versus metallic systems; and the interrelationship of several key parameters including heating rates, heat load and vehicle geometry, attitude, weight and aerodynamics. Trade studies were presented highlighting the importance of developing a trajectory for a particular TPS concept ${ }^{48,49}$ as well as the importance of mitigating early boundary-layer transition ${ }^{50}$. In Fig. 23, a sketch of the trends in heat load and rate are shown for consideration in selecting a low-heat-rate (metallic) or high-heat-rate, low-heat-load (ceramic) TPS. Generally speaking, the designer trades rates for loads on different entry trajectories. The high temperature capabilities and insulative nature of ceramics drive the designer to fly short, deep entry trajectories with high heat rate and low heat load (Fig. 24) whereas the metallic systems require low-heat-rate but higher heat-load trajectories to stay within the temperature limits. Figure 25 illustrates an approach to tailoring a trajectory with the knowledge of several heating constraints ${ }^{50}$. The upper boundary is the equilibrium glide boundary for a given lift loading coefficient and AOA and represents the minimum heating rate-profile that a vehicle could fly unconstrained under ideal conditions. The reference heating bound represents the heating profile that should be flown to provide the optimal heating/temperature conditions for a chosen TPS. The lower line represents a turbulent constraint. The altitude needs to be maintained at or above this limit until velocities are sufficiently low such that the temperatures associated with transition at that trajectory condition are within the capability of the selected TPS and do not exceed the peak laminar values that generally occur early in the entry. Figure 26 demonstrates the impact of applying a metallic hot structure to a trajectory tailored for a ceramic TPS compared to a trajectory actually optimized for a metallic hot structure ${ }^{49}$. The metallic materials that can tolerate the high heating rates/temperatures of a ceramic TPS trajectory are high-density materials and thus a significant weight penalty would be encountered. Significant heating, and therefore weight penalties, may also be incurred if the 
trajectory is optimized assuming laminar heating only without regard for the occurrence of transition and turbulent flow. Such a situation is depicted in Fig. 27. Peak centerline temperatures over the time of the trajectory are presented for two trajectories -- one tailored only for laminar heating and the second tailored with an additional constraint on turbulent heating. The second trajectory results in significantly lower temperatures since the trajectory was tailored to mitigate transition onset. The combined impact of lower temperatures and lower heat loads is presented in terms of TPS weight reduction in Ref. 50. It should be noted that the trade was based strictly on a tile TPS. Since the temperatures were lower as a result of delaying transition onset, an even greater weight savings could have been realized by using a lighter weight blanket TPS.

Until recently, the iteration to account for transition and turbulent heating in a trajectory development could be quite cumbersome. Previously, it was noted in this paper that an analytic method could be determined that represents a transition surface for a given value of the transition parameter in terms of the altitude, velocity and AOA expected over the vehicle entry corridor ${ }^{6,31}$. This analytic tool can be implemented in a trajectory code for the optimization of a trajectory, and the ensuing benefits are discussed in Ref. 31.

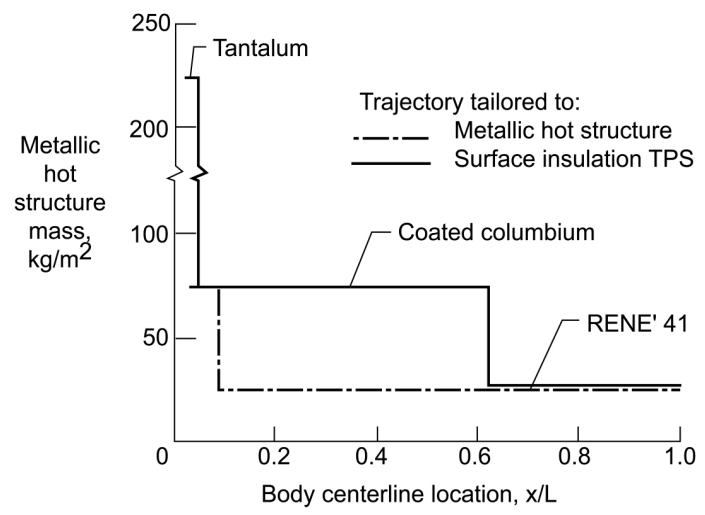

Fig. 26 Impact of tailored trajectories on metallic hot structure mass requirements.

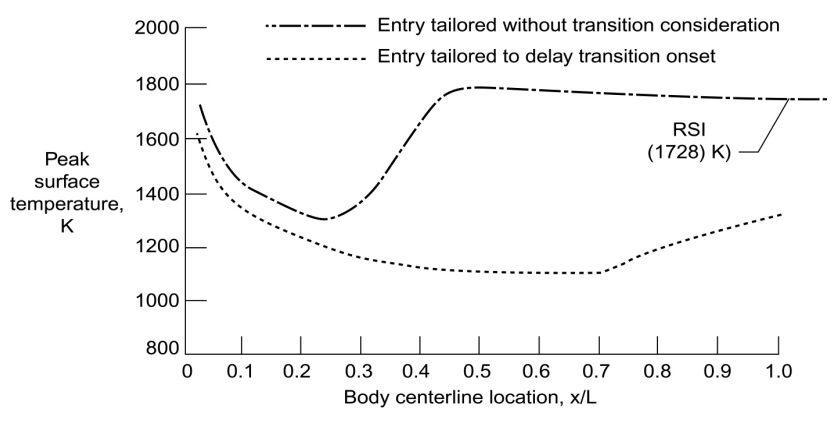

Fig. 27 Impact of laminar and turbulent trajectories on a ceramic TPS peak temperatures.

\section{B. Integration of Tools for Aeroheating Design}

This section provides an example of the integration of experimental and computational (engineering and CFD) efforts to produce a high quality detailed aeroheating database ${ }^{14}$ sufficient for the contractor to design the X-34 acreage TPS. The contractor required time-dependent heating environments at small time increments to perform the TPS thermal analysis. The environments generated by LaRC were used to select and size the acreage TPS as well as determine the TPS split lines. Due to time and resource constraints, it was not possible to populate the entry corridor with a large number of high quality heating solutions and then interpolate the resulting database for a 
specified trajectory. The selected approach first verified MINIVER with experimental data and then with the results of higher level heating predictions. The comparisons shown in Figs. 28(a-c) represent key results of that verification effort. It can be seen that the MINIVER code results are in good agreement with the experimental results (Fig. 28(a)) and detailed predictions (Figs. 28(b) and 28(c)). Several trajectory times were then selected based on peak heating for ascent and descent, windward and leeward, and to represent the AOA and Reynolds number range. Heating rates were computed at two of the selected times using LAURA in Ref. 36 and at all the selected times using LATCH in Ref. 51. These results were used to benchmark the MINIVER code that was then used to provide the required timedependent trajectory environments. The process is illustrated in Fig. 29 along with the equation used to provide the heating rates at small time intervals. In a clockwise direction, the first figure (upper left) represents a MINIVER predicted heating time history at a centerline body point. MINIVER was then compared with the LATCH centerline results, and augmentation factors at 14 body stations were computed. These factors were obtained at several of the trajectory times for which LATCH results were available. The next step was to obtain off centerline augmentation factors at each of the selected trajectory times by forming ratios of local LATCH heating rates at a cut plane to the corresponding centerline value. Prior to producing the heating at all the small time intervals at approximately one hundred body locations, an attempt was made to verify the analysis tool. For a selected trajectory time at which the LATCH results were available but were not used during the development of the engineering technique, the MINIVER heating rates were predicted with the equation given on Fig. 29 and the freestream conditions noted on Fig. 30. These results were compared with the LATCH results along the centerline and several cut planes. A good comparison of the heating results is shown in Fig. 30. This comparison provides the confidence that the engineering methodology ${ }^{14}$ was more than adequate for providing the required heating environments over the X-34 surface.

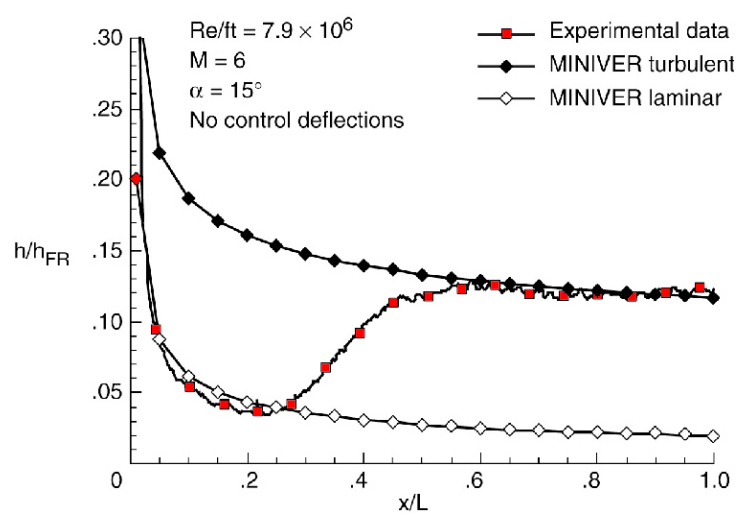

(a) Experimental data (thermographic phosphor)

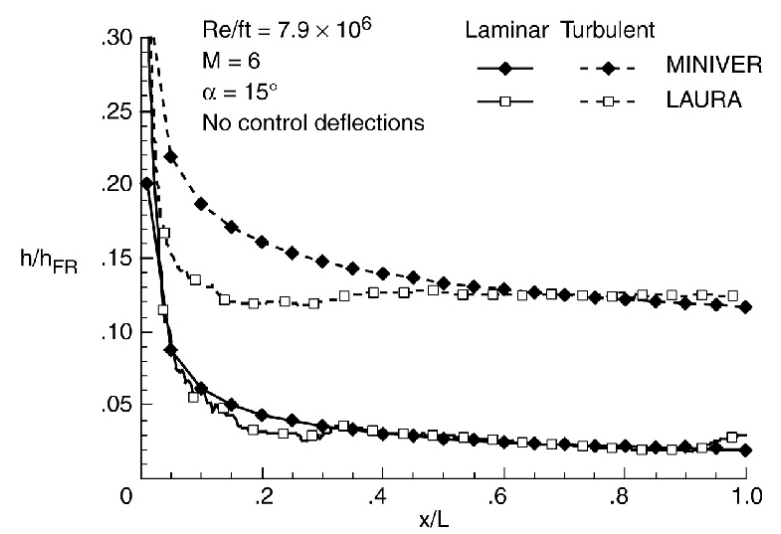

(b) LAURA viscous results.

Fig. 28 MINIVER X-34 heating comparisons. 


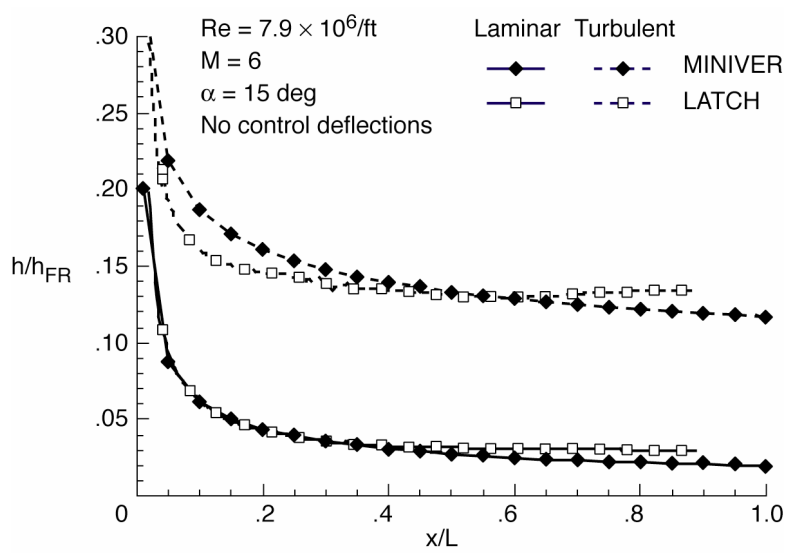

(c) LATCH results.

Fig. 28 MINIVER X-34 heating comparisons (cont'd).
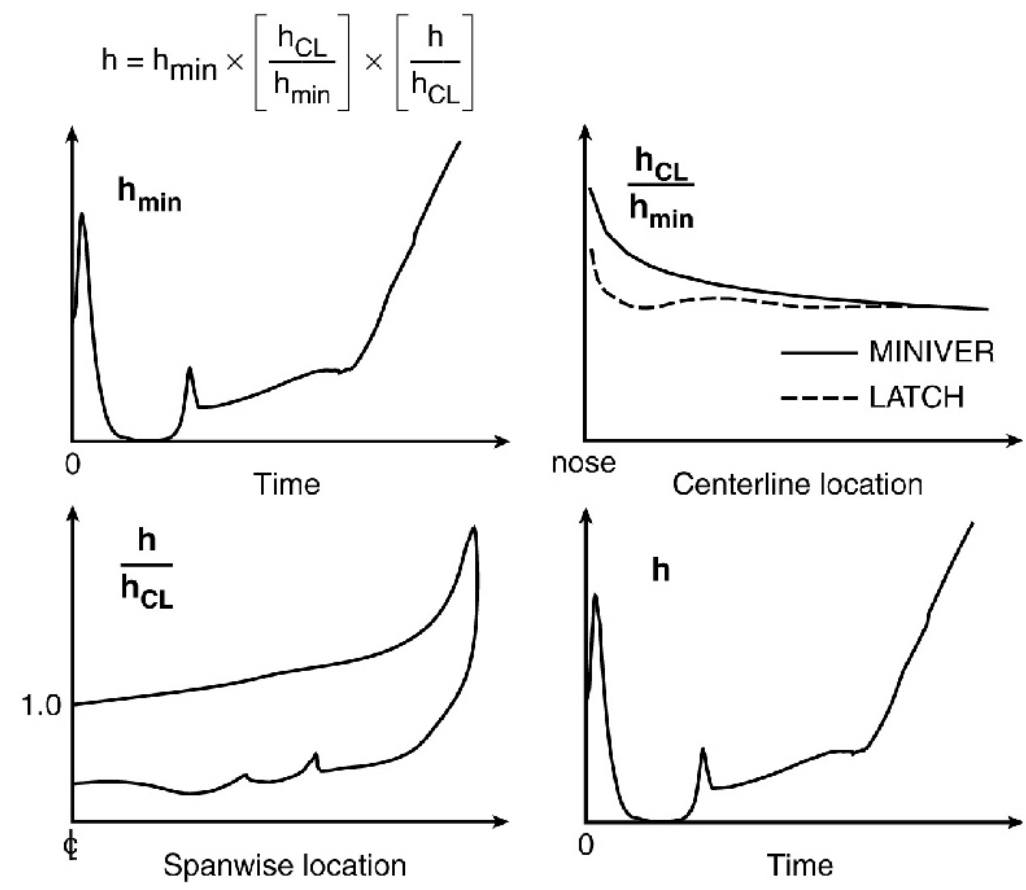

Fig. 29 X-34 Aeroheating design methodology. 


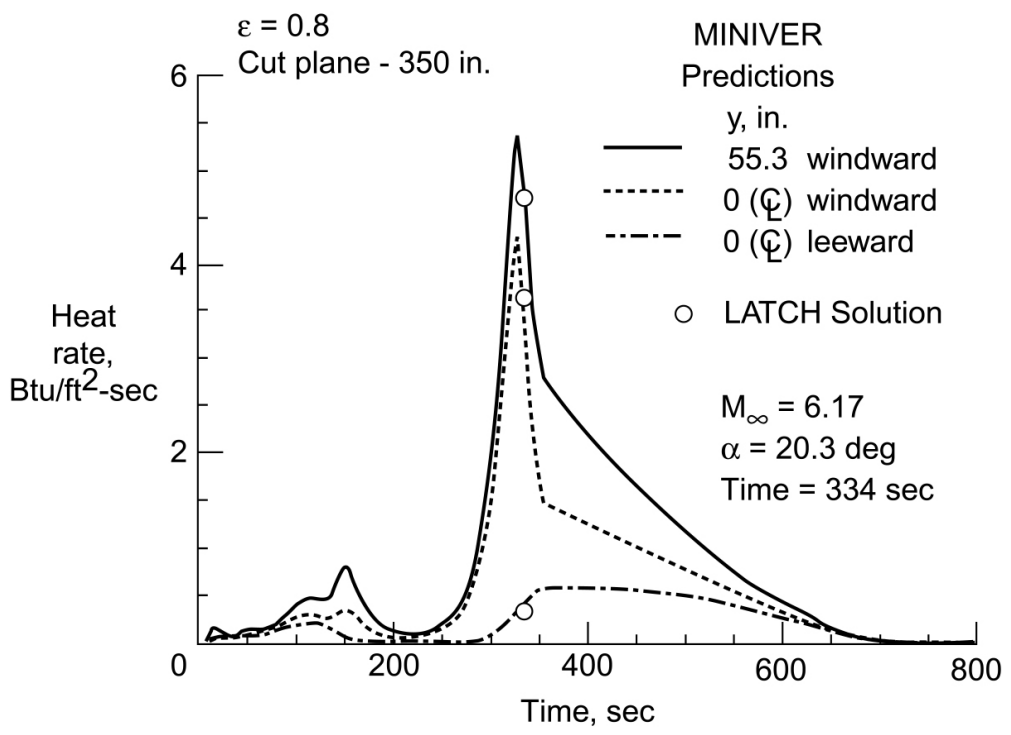

Fig. 30 Verification of MINIVER X-34 aeroheating methodology.

\section{Concluding Remarks}

The paper presents a perspective on aeroheating issues that can be significant to the design of a Reusable Launch Vehicle. The issues included computational and experimental topics, such as boundary-layer transition, shockshock interactions, Outer Mold Line shaping, low-density effects, uncertainties in material surface properties, and factors in design trajectory selection. The discussion of the issues focused primarily on the relevant information that can be obtained when appropriate tools are employed in an investigation. A discussion of a procedure used to produce an aeroheating database for Thermal Protection System design was also presented. The paper highlights the importance of properly utilizing and integrating all available data/predictions (experimental, CFD, and engineering) to obtain a reliable aeroheating database, suitable for successful RLV TPS design. While it is noted that all of the issues reviewed in the paper can ultimately affect a RLV design there were two topics that were especially noteworthy. One is the experimental result showing that a turbulent boundary layer upstream of a deflected flap may not represent peak heating conditions for the flap and thus could impact the TPS flap design. The other topic is the development of an analytical method using a transition indicator over the trajectory space of an entry vehicle. This analytical tool has been shown to aid in shaping trajectories to delay the boundary-layer transition. The application of this tool should produce savings with respect to material selection, weight and cost.

\section{Acknowledgments}

The authors gratefully acknowledge the support of Richard Wheless, NCI Information Systems, for his support in providing the graphics contained in the paper.

\section{References}

${ }^{1}$ Merski, N. R., "Global Aeroheating Wind-Tunnel Measurements Using Improved Two-Color Phosphor Thermography Method," Journal of Spacecraft and Rockets, Vol. 36, No. 2, 1999, pp. 160-170.

${ }^{2}$ Gnoffo, P. A., "Computational Aerothermodynamic Design Issues for Hypersonic Vehicles", Journal of Spacecraft and Rockets, Vol.36, No. 1, 1999, pp. 21-43.

${ }^{3}$ Hamilton, H. H., II, Greene, F. A., and DeJarnette, F. R., “Approximate Method for Calculating Heating Rates on ThreeDimensional Vehicles," Journal of Spacecraft and Rockets, Vol. 31, No. 3, 1994, pp. 345-354.

${ }^{4}$ Engel, C. D., and Praharaj, S. C., "MINIVER Upgrade for the AVID System, Vol. I: LANMIN User's Manual," NASA CR$172212,1983$.

${ }^{5}$ Micol, J. R, "Aerothermodynamic Measurement and Prediction for a Modified Orbiter at Mach 6 and 10 in Air," AIAA Paper 91-1436, June 1991.

${ }^{6}$ Thompson, R. A, Hamilton, H. H., II, Berry, S. A., Horvath, T. J., and Nowak, R. J., "Hypersonic Boundary-Layer Transition for X-33 Phase II Vehicle," AIAA Paper 98-0867, Jan. 1998.

${ }^{7}$ Berry, S. A., Horvath, T. J., Hollis, B. R., Thompson, R. A., and Hamilton, H. H., II, "X-33 Hypersonic Boundary-Layer Transition," Journal of Spacecraft and Rockets, Vol. 38, No. 5, 2001, pp. 646-657. 
${ }^{8}$ Miller, C.G., "Langley Hypersonic Aerodynamic/Aerothermodynamic Testing Capabilities, Present and Future." AIAA Paper 90-1376, June 1990.

${ }^{9}$ Zoby, E. V., Moss, J., N., and Sutton, K., “Approximate Convective-Heating Equations for Hypersonic Flows," Journal of Spacecraft and Rockets, Vol. 18, No. 1, 1981, pp. 64-70.

${ }^{10}$ Zoby, E. V., “Analysis of STS-2 Experimental Heating Rates and Transition Data,” Journal of Spacecraft and Rockets, Vol. 20, No. 3, May-June 1983, pp. 232-237.

${ }^{11}$ Zoby, E. V., Sutton, K., Olstad, W. B., and Moss, J., N., and Sutton, K., "An Approximate Inviscid Radiating Flow-Field Analysis for Outer Planet Entry Probes," Outer Planet Entry Heating and Thermal Protection, edited by R. Viskanta, Progress in Astronautics and Aeronautics, AIAA, New York, 1979, pp. 42-64.

${ }^{12}$ Wurster, K. E., Zoby, E. V., and Thompson, R. A., "Flowfield and Vehicle Parameter Influence on Results of Engineering Aerothermal Methods" Journal of Spacecraft and Rockets, Vol. 28, No. 1, 1991, pp. 16-22.

${ }^{13}$ Wurster, K. E., and Stone, H. W., "Aerodynamic Heating Environment Definition/Thermal Protection System Selection for the HL-20," Journal of Spacecraft and Rockets, Vol. 30, No. 5, 1993, pp. 549-557.

${ }^{14}$ Wurster, K. E., Riley, C. J., and Zoby, E. V., "Engineering Aerothermal Analysis for X-34 Thermal Protection System Design" Journal of Spacecraft and Rockets, Vol. 36, No. 2, 1999, pp. 216-228.

${ }^{15}$ King, R. A., "Three-Dimensional Boundary-Layer Transition on a Cone at Mach 3.5," Experiments in Fluids, Vol. 13,1992

${ }^{16}$ Mack, L. M., "Linear Stability Theory and the Problem of Supersonic Boundary-Layer Transition," AIAA Journal, Vol. 13, No. 3, March, 1975, pp 278-289.

${ }^{17}$ Stetson, K. F., and Kimmel, R. L., “On Hypersonic Boundary-Layer Stability,” AIAA Paper 92-0737, Jan., 1992.

${ }^{18}$ Krogmann, P., “An Experimental Study of Boundary-Layer Transition on a Slender Cone at Mach 5," AGARD-CP224, May, 1977.

${ }^{19}$ Mateer, G. G., and Larson, H. K., "Unusual Boundary-Layer Transition Results on Cones in Hypersonic Flow," AIAA Journal, Vol. 7, No. 4, April, 1969, pp 661-664

${ }^{20}$ Mack, L. M., "Stability of Axisymmetric Boundary Layers on Sharp Cones at Hypersonic Mach Numbers," AIAA Paper 87-1413, June 1987.

${ }^{21}$ Stetson, K. F., Thompson, E. R., Donaldson, J. C., and Siler, L. G., "Laminar Boundary Layer Stability Experiments on a Cone at Mach 8, Part 2: Blunt Cone," AIAA Paper 84-00006, Jan. 1984.

${ }^{22}$ Reshotko, E., "Boundary Layer Stability and Transition," Annual Review of Fluid Mechanics, Vol. 8, 1976, pp. 311-349.

${ }^{23}$ Bouslog, S. A., Bertin, J. J., Berry, S. A., and Caram, J. M., "Isolated Roughness Induced Boundary-Layer Transition: Shuttle Orbiter Ground Tests and Flight Experience," AIAA Paper 97-0274, Jan. 1997.

${ }^{24}$ Bertin, J. J., Hayden, T. E., and Goodrich, W. D., "Shuttle Boundary-Layer Transition due to Distributed Roughness and Surface Cooling," Journal of Spacecraft and Rockets, Vol. 19, No.5, 1982, pp. 389-396.

${ }^{25}$ Van Driest, E. R., and Blumer, C. B., "boundary Layer Transition on Cones and Spheres at Supersonic Speeds-Effects of Roughness and Cooling," U.S. Air Force Office of Scientific Research, Rept. 67-2048, July 1967.

${ }^{26}$ Boudreau, A. H., "Artificially Induced Boundary-Layer Transition on Blunt-Slender Cones at Hypersonic Speeds," Journal of Spacecraft and Rockets, Vol. 16, No. 4, 1979, pp. 245-251.

${ }^{27}$ Reed, H. L., Kimmel, R., Schneider, S., and Arnal, D., "Drag Prediction and Transition in Hypersonic Flow," AGARD-CP600, Vol. 3, Dec., 1997.

${ }^{28}$ Reda, D. C., "Review and Synthesis of Roughness-Dominated Transition Correlations for Reentry Applications," Journal of Spacecraft and Rockets, Vol. 39, No. 2, 2002, pp. 161-167.

${ }^{29}$ Stetson, K. F., and Rushton, G. H., "Shock tunnel Investigation of Boundary-Layer Transition at M=5.5," AIAA Journal, Vol. 5, No. 5, May, 1967, pp 899-906

${ }^{30}$ Berkowitz, A. M., Kyriss, C. L., and Martellucci, A., "Boundary Layer Transition Flight Test Observations," AIAA Paper 77-125, Jan. 1977

${ }^{31}$ Tartabini, P. V., Wurster, K. E., Korte, J. J., and Lepsch, R. A., "Multidisciplinary Analysis of a Lifting Body Launch Vehicle," Journal of Spacecraft and Rockets, Vol. 39, No. 5, 2002, pp. 788-795.

${ }^{32}$ Kontinos, D. A., and Palmer, G., "Numerical Simulation of Metallic Thermal Protection System Panel Bowing," Journal of Spacecraft and Rockets, Vol. 36, No. 6, 1999, pp. 842-849.

${ }^{33}$ CAIB Final Report. Vol. I, August, 2003.

${ }^{34}$ Horvath, T. J., "Experimental Aerothermodynamics in Support of the Columbia Accident Investigation," AIAA Paper 2004-1387, Jan. 2004.

${ }^{35}$ Berry, S. A., Horvath, T. J., DiFulvio, M., Glass, C., and Merski, N. R., "X-34 Experimental Aeroheating at Mach 6 and 10," Journal of Spacecraft and Rockets, Vol. 36, No. 2, 1999, pp. 171-178.

${ }^{36}$ Kleb, W. L., Wood, W. A., Gnoffo, P. A., and Alter, S. J., "Computational Aeroheating Predictions for X-34," Journal of Spacecraft and Rockets, Vol. 36, No. 2, 1999, pp. 179-188.

${ }^{37}$ Horvath, T. J., Berry, S. A., Hollis, B. R., Liechty, D. S., Hamilton, H. H., II, and Merski, N. R., "X-33 Experimental Aeroheating at Mach 6 Using Phosphor Thermography," Journal of Spacecraft and Rockets, Vol. 38, No. 5, 2001 , pp. $634-645$.

${ }^{38}$ Hollis, B. R., Thompson, R. A., Murphy, K. J., Nowak, R. J., Riley, C. J., Wood, W. A., Alter, S. J, and Prabhu, R. K., "X33 Aerodynamic Computations and Comparisons with Wind-Tunnel Data," Journal of Spacecraft and Rockets, Vol. 38, No. 5, 2001, pp. 684-691.

${ }^{39}$ Hollis, B. R., Horvath, T. J., Berry, S. A., Thompson, R. A., and Alter, S. A., "X-33 Computational Aeroheating Predictions and Comparisons with Experimental Data," Journal of Spacecraft and Rockets, Vol. 38, No. 5, 2001, pp. 658-669 
${ }^{40}$ Berry, S. A., Horvath, T. J., Weilmuenster, K. J., Alter, S. A., and Merski, N. R., "X-38 Experimental Aeroheating at Mach 10," Journal of Spacecraft and Rockets Vol. 41, No. 2, 2004, pp. 293-301.

${ }^{41}$ Horvath, T. J., Rhode, M. N., and Buck, G. M., "Aerothermodynamic Measurements on a Proposed Assured Crew Return Vehicle (ACRV) Lifting Body Configuration at Mach 6 and 10 in Air," AIAA Paper 90-1744, June 1990.

${ }^{42}$ Gupta, R. N., Zoby, E. V., and Lee, K. P. "Viscous Shock-Layer Analysis of Two-Dimensional and Axisymmetric Flows" Journal of Thermophysics and Heat Transfer, Vol. 8, No. 3, 1994, pp. 494-499.

${ }^{43}$ Miller, C. G., III, Micol, J. R., and Gnoffo, P. A., "Laminar Heat-Transfer Distributions on Biconics at Incidence in Hypersonic-Hypervelocity Flows,” NASA TP 2213, 1985.

${ }^{44}$ Gilbert, L. M. and Goldberg, L., “A Reynolds Number Scaling Theory for Hypersonic Ablation,” AIAA Paper 67-155, Jan. 1967.

${ }^{45}$ Stewart, D. A., "Surface Catalysis and Characterization of Proposed Candidate TPS for Access-to-Space Vehicles," NASA TM 112206, 1997.

${ }^{46}$ Cunningham, J. A., Rochelle, W. C., Norman, I., Ting, P. C., and Gallegos, J. J., "Shuttle Entry Air Data System (SEADS) Columbium Pressure Port Preflight Testing and Analysis," AIAA Paper 85-1021, June 1985.

${ }^{47}$ DeVenezia, J., Wang, K. C, and Caram, J. M."Space Shutttle Orbiter Wing Leading Edge Heating Predictions and Measurements," Proceedings of the Orbiter Experiments (OEX) Aerothermodynamics Symposium, NASA CP 3248, Part 2, Washington, DC, 1993, pp. 741-810.

${ }^{48}$ Wurster, K. E. and Eldred, C. H., "Technology and Operational Considerations for Low-Heat-Rate Trajectories," Journal of Spacecraft and Rockets, Vol. 17, No. 5, 1980, pp. 459-464.

${ }^{49}$ Wurster, K. E., "Lifting Entry Vehicle Mass Reduction Through Integrated Thermostructural/Trajectory Design," Journal of Spacecraft and Rockets, Vol. 20, No. 6, 1983, pp. 589-596.

${ }^{50}$ Wurster, K. E., "An Assessment of the Impact of Transition on Advanced Winged Entry Vehicle Thermal Protection System Mass," AIAA Paper 81-1090, June 1981.

${ }^{51}$ Riley, C. J., Kleb, W. L., and Alter, S. J., "Aeroheating Predictions for X-34 Using and Inviscid Boundary-Layer Method" Journal of Spacecraft and Rockets, Vol. 36, No. 2, 1999, pp. 206-215. 